\title{
MATEMATIZACIÓN DE LA GRAMÁTICA Y SU APLICACIÓN A LA ESTRUCTURA MORFOLÓGICA VERBAL DE LA LENGUA VASCA
}

\author{
JOSÉ FERNANDO DOMENE VERDÚ \\ joferdv@ono.com
}

\begin{abstract}
Resumen
La utilización de la teoría de conjuntos de las matemáticas como fundamento de la propuesta de matematización o axoiomatización de la gramática de las lenguas, en general, es posible. Los principios teóricos y metodológicos de la reconstrucción interna de las lenguas se han aplicado a numerosos datos dialectales de la morfología verbal de lengua vasca, verificando que todos ellos cumplen las leyes fonéticas de dicha lengua. Determinados los elementos del sistema morfológico verbal vasco, ha sido posible reconstruir los distintos estadios evolutivos o fases, de manera que la morfología verbal de la lengua vasca que se hablaba antes de la romanización ha podido ser conocida en profundidad, todo gracias a la utilización del método matemático basado en la teoría de conjuntos.
\end{abstract}

PALABRAS CLAVE: lengua vasca, morfología verbal, teoría de conjuntos, reconstrucción interna de las lenguas.

\begin{abstract}
The use of mathematical Theory of Sets for a proposal of mathematization or axiomatization of the Grammar of languages in general is possible. Following the theoretical and methodological principles of the comparative method of internal reconstruction of languages, all the verbal dialectal data known of the Basque Language have been analyzed, proving that all of them satisfy the phonetical laws of this language. Once all the elements included in the verbal morphological system of the Basque language have been searched and established, it has been possible to make the reconstruction of its historical formation process, and to know all its evolutional and chronological phases. In this way, verbal morphology of the Basque language spoken before the Roman has been known profoundly. Thanks to the mathematical method used in this searching disstertation, all these explanations have been made successfully.

KEYWORDS: Basque Language, Verbal Morphology, Theory of Sets, Internal Reconstruction of Languages.
\end{abstract}

\section{Introducción}

Ferdinand de Saussure (1916: 338), basándose en el principio de que "la retrospección exige un método reconstructivo, que se apoya en la comparación", afirmó hace casi un siglo que "no se puede sacar nada del vascuence porque, estando aislado, no se presta a comparación alguna". Después, Antoine Meillet aceptó esta idea (1925: 12) y la extendió también a la comparación interna ${ }^{1}$ basándose en la similitud entre la lengua vasca moderna

\footnotetext{
1 "De ce que la méthode comparative est la seule que permette de faire l'histoire des langues il résulte que, tant qu'une langue est isolée, elle est denué d'histoire. Entre l'etat du basque en $\mathrm{XVI}^{\mathrm{e}}$ siècle et l'etat du basque aujourd'hui, il y a des differénces; mais les changements ne sont pas essentiels; en substance, la langue est restée la même. Si donc on retrouve pas de moyen de rapprocher le basque de telle on telle autre langue, il n'y aurait aucun espoir d'en faire jammais l'histoire." (Meillet, 1925: 12.).
} 
y la de los primeros textos literarios, que son del siglo XVI (Dechepare, 1545; Leizarraga, 1571; Refranes y Sentencias, 1596; Betolaza, 1596) ${ }^{2}$. Sin embargo, G. Bonfante (1945) mostró su desacuerdo con tan pesimista afirmación y, años más tarde, L. Michelena ${ }^{3}$ (1963: 17) demostró, además, que Saussure y Meillet estaban en un error (Michelena, 1961).

Ciertamente, es posible conocer el pasado de una lengua aislada gracias al método de reconstrucción interna, en virtud del cual "una lengua, desde el punto de vista diacrónico constituye un sistema que retiene cierta información sobre su propio pasado, sobre sus fases anteriores" (Michelena, 1963, 11), ya que una lengua no evoluciona de manera uniforme en todo el territorio en el que se habla, sino más rápidamente en unas áreas que en otras ${ }^{4}$. El mejor ejemplo de su aplicación es la Fonética Histórica Vasca, de Luis Michelena (1961). Sin embargo, su aplicación a las demás partes de la lingüística vasca, como por ejemplo la morfología, no ha sido tan afortunada ya que en ella no se han producido avances significativos y los resultados no tienen la certeza de los obtenidos en la fonética ni gozan muchas veces de la aceptación unánime de la comunidad lingüística ${ }^{5}$. A ello, ha contribuido, sin duda, la complejidad y variabilidad dialectal de su sistema morfológico verbal.

\footnotetext{
${ }^{2}$ Los primeros textos conocidos son algo anteriores (Michelena, 1964a; Sarasola, 1983; Michelena y Sarasola, 1988). Las primeras gramáticas de la lengua vasca, en cambio, son del siglo XVII (Axular, 1643; Micoleta, 1653; Oihenart, 1656), aunque destaca sobre todas ellas la gramática y el diccionario de Larramendi $(1729,1745)$.

3 "Una lengua, repetimos, aun considerada en un aislamiento total y en un punto de su evolución, contiene información más o menos implícita sobre estados anteriores que puede explicitada, si se trata adecuadamente" (Michelena, 1963: 17).

${ }^{4}$ El método de reconstrucción interna de la lengua parte del supuesto de que la lengua no evoluciona de manera uniforme en todo el territorio en el que dicha lengua se habla; esto es, en unas áreas la lengua evoluciona más rápidamente que en otras; de ahí que, toda lengua, sea cual sea la fase de evolución histórica considerada, conserva restos de las fases anteriores. El estudio comparado de estos restos es lo que permite la reconstrucción de los distintos estadios evolutivos de dicha lengua. Dicho de otra manera (Michelena, 1963: 39), "una lengua, desde el punto de vista diacrónico constituye un sistema que retiene cierta información sobre su propio pasado, sobre sus fases anteriores". Por lo que al aspecto metodológico se refiere, Michelena (1963: 39) puntualizó que la reconstrucción interna y externa comparten "los mismos principios y emplean esencialmente las mismas técnicas"; pues si en la reconstrucción externa se comparan formas lingüísticas de dos o más lenguas a fin de establecer los rasgos de una lengua común de la que éstas pudieran proceder; es decir, si el objetivo es determinar la afiliación genética de las lenguas, llegando incluso a perfilar los rasgos de una lengua común de la que no existen testimonios -protolengua-; en la reconstrucción interna se comparan formas lingüísticas de una misma lengua a fin de determinar una o más secuencias evolutivas de ésta de las que no se tiene constancia alguna. El método de reconstrucción interna resulta imprescindible "cuando una lengua aislada (genéticamente aislada, se entiende) carece de historia, o cuando, a partir de sus primeros testimonios, queremos remontarnos a la prehistoria" (Michelena, 1963: 39).

${ }^{5}$ En efecto, como afirman Gorrochategui y Lakarra (1996: 129), "parece evidente que la investigación en morfología histórica vasca y, consecuentemente, en la reconstrucción morfológica del protovasco ha ido y va más retrasada que la referente a la de los sonidos". Y estos mismos autores apuntan las bases y la dirección en la debe avanzar la investigación en la morfología histórica, que no es otra que la dialectología: "La comparación dialectal y el establecimiento de la dialectología diacrónica son, también, tareas imprescindibles que corren parejas a la reconstrucción de la morfología nominal y verbal. El estudio de las formas dialectales más antiguas y su análisis comparativo con el objeto de discernir las innovaciones morfológicas recientes de los arcaísmos perdurables proporcionarán, por un lado, los argumentos necesarios para el establecimiento de una historia de la lengua vasca y constituirán, por otro, la base más segura para la proyección de una reconstrucción hacia la prehistoria" (Gorrochategui y Lakarra 1996: 136).
} 
El objetivo de este trabajo es contribuir al conocimiento de la morfología verbal vasca en su vertiente diacrónica mediante la reconstrucción interna, determinando el origen y funciones gramaticales de todos los morfemas verbales y la sucesión de fases que constituyen el proceso de formación del sistema morfológico verbal vasco. Para ello, es imprescindible, por una parte, el estudio de las distintas formas verbales dialectales, y por otra, el conocimiento de las leyes fonéticas que están en el origen de esas variantes dialectales. La lengua vasca es privilegiada en ambos aspectos, ya que cuenta con estudios serios y adecuados para ello como el Erizkizundi Irukoitza o Triple Cuestionario realizado en los años veinte (Euskaltzaindia, 1925-1930; Echaide, 1974, 1984) y la Fonética Histórica Vasca de Luis Michelena, publicada en 1961, que es un estudio impecable y riguroso de obligada consulta para cualquier estudioso de esta lengua; y "cedazo por el que han de pasar necesariamente tantas hipótesis y teorías morfológicas anteriores" (Gorrochategui y Lakarra 1996: 130).

La lengua vasca se caracteriza por la gran diversidad dialectal que presenta en un territorio muy reducido, lo que la hace especialmente adecuada para la reconstrucción interna. La clasificación dialectal de L. L. Bonaparte (1963) fue el primer estudio dialectológico que se realizó en Europa y ha sido seguida después por la mayoría de los lingüistas, entre ellos P. de Yrízar $(1973,1975,1981)$. Se trata del mapa de los dialectos vascos, que publicó en Londres en 1863, trece años antes de que G. Wenker publicara las primeras encuestas dialectológicas en Alemania en 1876 y casi medio siglo antes de que J. Gilliéron publicara el Atlas Linguistic de la France. La clasificación de L. L. Bonaparte constaba de ocho dialectos: vizcaíno (V), guipuzcoano $(\mathrm{G})$, labortano (L), alto-navarro meridional (ANM), alto-navarro septentrional (ANS), bajo-navarro oriental (BNOr), bajonavarro occidental (BNOc) y suletino (S). R. M. de Azkue (1905-1906) diferenció el dialecto roncalés $(\mathrm{R})$ y unificó los dos dialectos alto-navarros (AN) y los dos bajo-navarros (BN), mientras que L. Michelena (1961) diferenció el antiguo dialecto de Álava, que llamó meridional, y los tres dialectos pirenaicos: el roncalés, el salacenco y el aezcoano. 


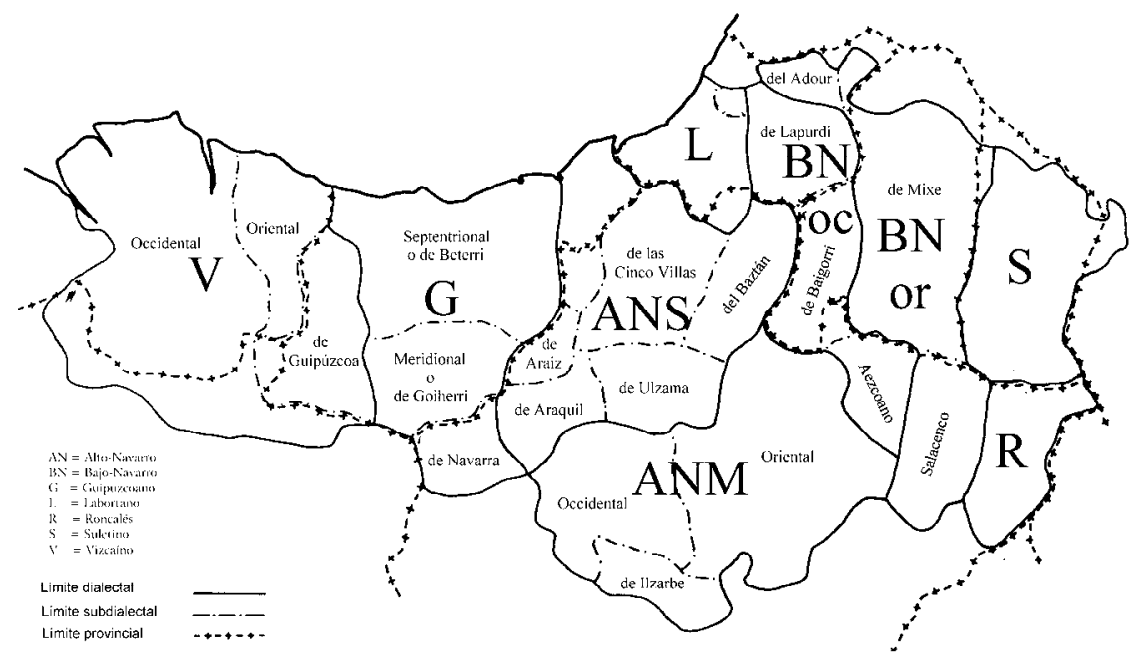

Mapa 1. Los dialectos vascos en el siglo XIX. Clasificación dialectal de Bonaparte $(1863,1869)$ con la individualización del roncalés (Azkue).

La investigación de los últimos años sobre la dialectología vasca ha permitido comprobar que se han producido cambios significativos en los dialectos vascos y K. Zuazo (1998a: 22; 1998b) ha establecido un nuevo mapa de los dialectos vascos (euskalkiak) en su estado actual, que utiliza nuevos criterios y una nueva terminología para ellos: occidental en vez de vizcaíno, central en vez de guipuzcoano, navarro en vez de alto-navarro, navarro oriental, que agrupa al salacenco y al roncalés, y navarro-labortano, que agrupa al labortano y al bajo-navarro. También ha modificado los límites de casi todos ellos, adjudicando algunos subdialectos (aezcoano, salacenco) y hablas de transición a los dialectos vecinos (Camino, 1997) y considerando algunos dialectos como subdialectos (el labortano y el bajo-navarro oriental y occidental forman el dialecto navarro-labortano, el alto-navarro septentrional y meridional forman el dialecto navarro junto al aezcoano, y el roncalés forma el navarro oriental junto al salacenco). 


\begin{tabular}{|c|c|c|c|c|c|}
\hline $\begin{array}{c}\text { Zona } \\
\text { geográfica }\end{array}$ & $\begin{array}{c}\text { Bonaparte } \\
\text { (1869) }\end{array}$ & $\begin{array}{l}\text { Azkue } \\
\text { (1905) }\end{array}$ & $\begin{array}{c}\text { Michelena } \\
\text { (1961) }\end{array}$ & $\begin{array}{l}\text { Yrizar } \\
\text { (1981) }\end{array}$ & $\begin{array}{l}\text { Zuazo } \\
(1998) \\
\end{array}$ \\
\hline Vizcaya & \multirow[t]{2}{*}{ B } & \multirow[t]{2}{*}{$\mathrm{B}$} & $\mathrm{B}$ & \multirow[t]{2}{*}{$\mathrm{B}$} & \multirow{2}{*}{ Occidental } \\
\hline Álava & & & Meridional & & \\
\hline Guipúzcoa & $\mathrm{G}$ & $\mathrm{G}$ & $\bar{G}$ & $\mathrm{G}$ & Central \\
\hline \multirow{2}{*}{$\begin{array}{l}\text { Alta } \\
\text { Navarra }\end{array}$} & ANM & \multirow[t]{2}{*}{$\mathrm{AN}$} & ANM & ANM & \multirow[b]{2}{*}{ Navarro } \\
\hline & ANS & & ANS & ANS & \\
\hline Lapurdi & $\mathrm{L}$ & $\mathrm{L}$ & $\mathrm{L}$ & $\mathrm{L}$ & Navarro-Labortano \\
\hline \multirow{4}{*}{$\begin{array}{l}\text { Baja } \\
\text { Navarra }\end{array}$} & \multirow[t]{2}{*}{ BNOc } & \multirow[t]{4}{*}{$\mathrm{BN}$} & $\mathrm{BNOc}$ & \multirow[t]{2}{*}{$\mathrm{BNOc}$} & \\
\hline & & & Aezcoano & & Navarro \\
\hline & \multirow[t]{2}{*}{ BNOr } & & BNOr & \multirow[t]{2}{*}{ BNOr } & Navarro-Labortano \\
\hline & & & Salacenco & & Navarro Oriental \\
\hline Zuberoa & \multirow[t]{2}{*}{$\mathrm{S}$} & $\mathrm{S}$ & $\mathrm{S}$ & \multirow[t]{2}{*}{$\mathrm{S}$} & Suletino \\
\hline Roncal & & $\mathrm{R}$ & $\mathrm{R}$ & & Navarro Oriental \\
\hline
\end{tabular}

Esquema 1. Clasificaciones dialectales modernas.

La lengua vasca también es especialmente adecuada para la reconstrucción interna por la riqueza y complejidad de su morfología debido a su carácter aglutinante. En este tipo de lenguas, cada morfo representa un único morfema y la ausencia de sincretismo hace que aumente el número de morfemas y la regularidad de todo el sistema, siendo entonces muy importante cualquier irregularidad por pequeña que sea. Por ejemplo, $d$-i-e-za-zki-da-ke-zu$e=$ 'vosotros/as me los/las podéis haber' presenta 9 morfemas y z-e-n-i-e-za-zki-da-ke-te-n = 'vosotros/as me los/las hubierais podido haber' presenta 11. El gran número de datos a tener en cuenta -hemos podido contabilizar 18.932 formas verbales sintéticas- ha hecho necesaria la utilización de un instrumento teórico-metodológico que posibilite el tratamiento simplificado de los datos y el rigor científico que garantice la fiabilidad de los resultados. Ese instrumento son las matemáticas, que si bien ya se utilizan desde hace siglos en otras ciencias, su utilización en lingüística ha sido poco fructífera.

\begin{tabular}{|l|l|l|l|l|l|l|l|}
\hline & Tipos & Tiempos & $\mathbf{N}^{\mathbf{0}}$ & Total & Total & Modos & Total \\
\hline \multirow{4}{*}{$\begin{array}{l}\text { Formas } \\
\text { verbales }\end{array}$} & \multirow{2}{*}{ alocutivo } & presente & 175 & \multirow{3}{*}{40} & & & \\
\cline { 3 - 5 } & & pasado & 165 & 440 & \multirow{3}{*}{956} & 22 & \multirow{2}{*}{18.932} \\
\cline { 3 - 5 } & no alocutivo & presente & 264 & 516 & & & \\
\cline { 3 - 5 } & & pasado & 253 & & & & \\
\hline
\end{tabular}

Tabla 1: Número de formas verbales de la conjugación vasca. 


\section{Metodología}

\subsection{La Lingüística Matemática}

La Lingüística Matemática nació simultáneamente en la U.R.S.S. y en Estados Unidos a mediados de los años cincuenta como consecuencia de la aparición de los ordenadores. En ella, una gramática formal es un tipo particular de sistema axiomático ${ }^{6}$, que es "una estructura matemática definida por un cuadruplete $<\mathrm{V}, \mathrm{F}, \mathrm{A}, \mathrm{R}>$ donde $\mathrm{V}$ es un conjunto finito de símbolos llamado alfabeto o vocabulario; $\mathrm{F}$ es un lenguaje formal sobre $\mathrm{V}$, llamado conjunto de fórmulas bien formadas; A es un subconjunto de F, llamado conjunto de los axiomas; R es un conjunto de reglas de derivación", (Serrano, 1977: 188-189). Una gramática generativa se definió, entonces, como un sistema axiomático semithueano, $\mathrm{G}=$ $<\mathrm{V}_{\mathrm{T}}, \mathrm{V}_{\mathrm{N}}, \mathrm{S}, \mathrm{R}>$, que está formado por "un vocabulario fundamental o terminal, un vocabulario auxiliar, un símbolo inicial y una serie de reglas de reescritura" (Gladkij y Melchuk, 1972: 56), de tal manera que el "símbolo inicial" es el axioma inicial de los sistemas axiomáticos y, como en éstos, pertenece al vocabulario auxiliar ${ }^{7}$. Las reglas gramaticales serían funciones recursivas de tipo semithueano ${ }^{8} \mathrm{y}$, por tanto, aplicaciones ${ }^{9}$.

\footnotetext{
${ }^{6}$ Un sistema axiomático es un álgebra definida en el conjunto de símbolos denominado alfabeto, que lleva asociadas las reglas de inferencia, que son las leyes de composición interna u operaciones definidas en él. Igualmente, un sistema axiomático extendido es también un álgebra, pero esta vez definida en la unión de los conjuntos denominados alfabeto auxiliar y alfabeto básico. Un álgebra $\mathbf{A}$ es un conjunto A en el que se define una $\mathrm{o}$ varias leyes de composición y se representa por el conjunto $\mathrm{A}$ en el que se definen las leyes de composición y por las leyes de composición mismas, $\mathbf{A}=(\mathrm{A}, \mathrm{l}, \zeta)$ o $\mathbf{A}=+\mathrm{A},+,{ }_{\text {, }}$, aunque estas últimas se pueden sustituir por letras, de la forma $\mathbf{A}=\left(A, f_{1}, f_{2}, \ldots, f_{n}\right)$. Un álgebra recibe también el nombre de estructura algebraica.

${ }^{7}$ Por lo tanto, los conjuntos que lo forman son $V_{T}, V_{N}, S$ y $R$, siendo $R$ el conjunto de reglas de escritura que actúa sobre la unión de los conjunto $\mathrm{V}_{\mathrm{T}} \mathrm{y} \mathrm{V}_{\mathrm{N}}$, y siendo $\mathrm{S}$ un elemento de $\mathrm{V}_{\mathrm{N}}$. Las reglas gramaticales serían funciones recursivas de tipo semithueano y, por tanto, aplicaciones $\mathrm{f}: \Sigma \rightarrow \Sigma$, tal que $\Sigma=\mathrm{V}_{\mathrm{T}} \chi \mathrm{V}_{\mathrm{N}}$ y cuyos pares ordenados presentan la forma $(\psi, \omega)$, representada habitualmente por $\psi \rightarrow \omega$ y que se lee ' $\psi$ se reescribe $\omega$ ': $G=\left\langle V_{T}, V_{N}, S\right.$, $\mathrm{R}>$, tal que $\mathrm{R}=\left(\mathrm{x}_{1}, \mathrm{x}_{2}, \ldots, \mathrm{x}_{\mathrm{n}-1}, \mathrm{x}_{\mathrm{n}}\right) \rightarrow \mathrm{x}_{1}, \mathrm{x}_{2}, \ldots, \mathrm{x}_{\mathrm{n}-1} \quad \mathrm{x}_{\mathrm{n}}$. Teniendo en cuenta que un álgebra $\mathrm{A}$ es un conjunto $\mathrm{A}$ en el que se define una o más leyes de composición $\mathrm{f}_{1}, \mathrm{f}_{2}, \ldots, \mathrm{f}_{\mathrm{n}} \mathrm{y}$ se representa por $\mathrm{A}=<\mathrm{A}, \mathrm{f}_{1}, \mathrm{f}_{2}, \ldots, \mathrm{f}_{\mathrm{n}}>$, una gramática formal es, por tanto, un álgebra y, más concretamente, un monoide definido en la unión de $\mathrm{V}_{\mathrm{T}} \mathrm{y} \mathrm{V}_{\mathrm{N}}$, o sea en $\mathrm{V}_{\mathrm{T}} \chi$ $\mathrm{V}_{\mathrm{N}}$, teniendo en cuenta que $\mathrm{S} 0 \mathrm{~V}_{\mathrm{N}}$ y que las leyes de composición interna u operaciones asociadas forman el conjunto $\mathrm{R}$ de las reglas de reescritura. El conjunto $\mathrm{R}$ de las reglas de reescritura representa la concatenación de los elementos de $\mathrm{V}_{\mathrm{T}} \chi \mathrm{V}_{\mathrm{N}}$ y se puede representar por el símbolo \{, con lo cual \{ sería la ley de composición interna (por ejemplo, $\mathrm{a}\{\mathrm{b}\{\mathrm{c}\{\ldots\{\mathrm{n}$ ), que es asociativa y tiene elemento neutro, pero no simétrico, por lo que el conjunto $\Sigma=$ $\mathrm{V}_{\mathrm{T}} \chi \mathrm{V}_{\mathrm{N}}$ en el que se define no es un grupo, sino sólo un monoide. La concatenación, que es la ley de composición interna $\left\{\right.$ definida en el monoide, no sería más que una relación binaria de orden definida en el conjunto $\Sigma=\mathrm{V}_{\mathrm{T}} \chi$ $\mathrm{V}_{\mathrm{N}}$, que forma una serie de cadenas cuyos elementos pueden ser también, a su vez, cadenas (Partee, Ter Meulen, Wall, 1990: 434). Por lo tanto, una gramática formal es un monoide en el que se define una ley de composición interna denominada concatenación, que es asociativa y tiene elemento neutro, pero carece de simétrico, por lo que el conjunto $\Sigma=\mathrm{V}_{\mathrm{T}} \chi \mathrm{V}_{\mathrm{N}}$ en el que se define no llega a ser un grupo.

${ }^{8}$ Un tipo concreto de sistema axiomático extendido es aquél en el que las fórmulas de las reglas de inferencia, que son las leyes de composición interna, son binarias y constan de 3 elementos, fórmulas o secuencias de símbolos, de las cuales sólo una es la que cambia mientras que las otras dos permanecen invariables. Se representaría de la forma $\forall \mathrm{x} \exists 6 \forall \mathrm{y} \exists$, donde $\mathrm{x}$ e $\mathrm{y}$ son las fórmulas que cambian $\mathrm{y} \forall \mathrm{y} \exists$ las que permanecen invariables, $\mathrm{y}$ es conmutativo $(\forall \mathrm{y} \exists 6 \forall \mathrm{x} \exists$ ). Este tipo de sistema axiomático fue estudiado por primera vez por el matemático noruego Axel Thue, por lo que recibió el nombre de sistema axiomático thueano en su honor. Un sistema axiomático thueano que no es conmutativo se denomina semi-thueano., y en él sólo es posible la operación $\forall \times \exists G$
} 
Una gramática generativa es, por tanto, un álgebra definida en el vocabulario de un lenguaje formal y en la que las leyes de composición interna u operaciones son las reglas de reescritura de ese lenguaje formal. Para A. M. Tarski (1972) y R. Montague (1973), la Sintaxis y la Semántica se relacionan entre sí mediante un homomorfismo f: A 6 B entre dos álgebras ${ }^{10}$, el álgebra sintáctica y el álgebra semántica, y ese homomorfismo ${ }^{11}$ se denomina interpretación semántica.

\footnotetext{
$\forall \mathrm{y} \exists$, pero no la $\forall \mathrm{y} \exists 6 \forall \mathrm{x} \exists$ : "A semi-thue system is an e.a.s. (A, B, S, P) in which every production schema is binary and of the form $\forall \mathrm{x} \exists 6 \forall \mathrm{y} \exists$, where $\mathrm{x}$ and $\mathrm{y}$ are strings on (A $\chi \mathrm{B}$ )* and $\forall$ and $\exists$ are variables taking as values strings on $(\mathrm{A} \chi \mathrm{B})^{*}[\ldots]$. A thue system differs from a semi-thue system in that for every production schema $\forall \mathrm{x} \exists 6 \forall \mathrm{y} \exists$, the system also contains the inverse schema $\forall \mathrm{y} \exists 6 \forall \mathrm{x} \exists$ " (Partee-Meuler-Wall, 1990, 192). Sistema Thueano = e.a.s. $=<\mathbf{A}, \mathbf{B}, \mathbf{S}, \mathbf{P}>: \quad \mathbf{P}=\forall \mathrm{x} \exists 6 \forall \mathrm{y} \exists \varpi \forall \mathrm{y} \exists 6 \forall \mathrm{x} \exists$ Sistema Semithueano = e.a.s. $=<\mathbf{A}, \mathbf{B}, \mathbf{S}$, $\mathbf{P}>: \quad \mathbf{P}=\forall \mathrm{x} \exists 6 \forall \mathrm{y} \exists$. Los sistemas semithueanos, aunque pertenecen completamente a la lógica, son fundamentales en la lingüística matemática porque se han utilizado para definir las gramáticas generativas: "De los sistemas axiomáticos formales podríamos pasar a un tipo particular de ellos, los llamados sistemas combinatorios, entre los que se incluyen los sistema semitueanos que incluyen, a su vez, las gramáticas generativas" (Serrano, 1977: 189). O sea, que la gramática generativa de un lenguaje formal cualquiera es un tipo particular de sistema semithueano y, por lo tanto, de sistema axiomático.

${ }^{9}$ Aplicación es toda correspondencia unívoca cuyo dominio coincide con el conjunto inicial. Una correspondencia definida entre dos conjuntos A y B es todo subconjunto $\mathrm{G}$ del producto cartesiano de A y B. Al conjunto A se le denomina conjunto inicial; al B, conjunto final y al subconjunto $\mathrm{G}$, grafo de la correspondencia. Siendo A y B los conjuntos inicial y final de una correspondencia $\mathrm{f}$, se dice que f es unívoca si la imagen de cualquier elemento de $\mathrm{A}$ es un conjunto unitario o vacío. El producto cartesiano de dos conjuntos A y B es el conjunto $\mathrm{P}$ de todos los pares ordenados que se pueden formar con elementos de A y B. Par es todo conjunto que tiene dos elementos. Dados dos conjuntos no vacíos A y B, se llama par ordenado al ente (x, y), tal que x pertenece a A e y pertenece a $\mathrm{B}$.

${ }^{10}$ Como se ha dicho anteriormente, un álgebra $\mathbf{A}$ es un conjunto $\mathrm{A}$ en el que se define una o varias leyes de composición y se representa por el conjunto $\mathrm{A}$ en el que se definen las leyes de composición y por las leyes de composición mismas, $\mathbf{A}=(\mathrm{A}, \mathrm{l}, \zeta)$ o $\mathbf{A}=+\mathrm{A},+, \times$, aunque estas últimas se pueden sustituir por letras, de la forma $A=\left(A, f_{1}, f_{2}, \ldots, f_{n}\right)$. Un álgebra recibe también el nombre de estructura algebraica.

${ }^{11} \mathrm{Si}$ una correspondencia entre dos álgebras es una aplicación (o sea, que todo elemento de A tiene imagen y sólo una imagen), se denomina un morfismo (u homomorfismo), que se define como toda aplicación f: A 6 B entre dos álgebras $(\mathrm{A}, \square)$ y $(\mathrm{B}, \sim)$ tal que $\mathrm{f}(\mathrm{a} \square \mathrm{b})=\mathrm{f}(\mathrm{a}) \sim \mathrm{f}(\mathrm{b}), \square \mathrm{a} 0 \mathrm{~A}, \square \mathrm{b} 0$ B. Si la aplicación es inyectiva (algún elemento de B no tiene antiimagen en A pero los que tienen antiimagen sólo tienen una) se llama monomorfismo, si es suprayectiva (todo elemento de B tiene antiimagen en A y alguno puede tener más de una) es un epimorfismo (u homomorfismo) y si es biyectiva (todo elemento de B tiene antiimagen y sólo una antiimagen en A), es un isomorfismo.
} 

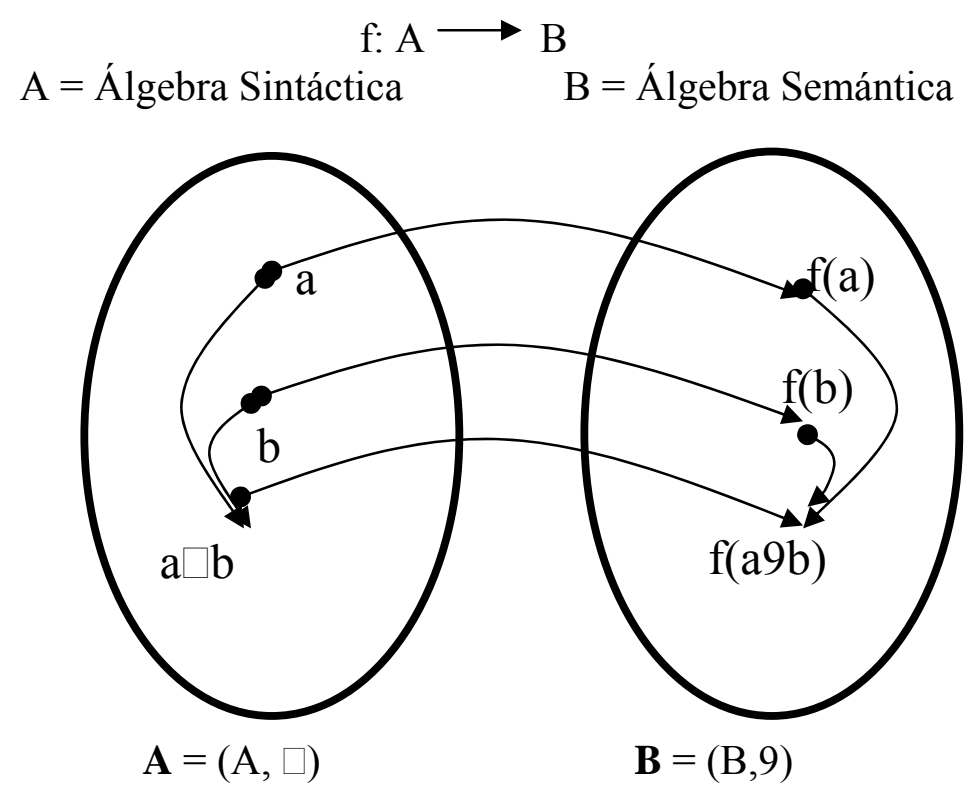

Ilustración 1. Homomorfismo definido entre el Álgebra Sintáctica y el Álgebra Semántica.

\subsection{Propuesta de matematización de la gramática de las lenguas}

La Lingüística Matemática se ha aplicado a la matematización de los lenguajes formales, como los de la lógica y la informática, que son simples (ya que sólo tienen sintaxis), regulares (porque no presentan excepciones) y unívocos (pues cada término corresponde a un solo significado y cada significado a un solo término). Sin embargo, no ha sido tan eficaz a la hora de aplicarla a los lenguajes naturales, ya que las lenguas constituyen sistemas complejos, irregulares y con un cierto grado de ambigüedad ${ }^{12}$.

La teoría de conjuntos, por el contrario, es la parte de las matemáticas más idónea para su aplicación a la lingüística y sí puede ocuparse las irregularidades de las lenguas y de la Lingüística Histórica. Sobre ella, hemos definido los conceptos lingüísticos básicos de análisis morfológico de las lenguas, formando un conjunto de conceptos unívocos y con coherencia lógica, expresándolos por medio de símbolos que permiten observar con mayor

\footnotetext{
${ }^{12}$ En efecto, la lingüística matemática ha conseguido resultados con las lenguas formales o artificiales, pero no con las lenguas naturales, y ello es reconocido por los mismos especialistas. Así, el mismo Harris (1971) definió matemáticamente el concepto de gramática o de lengua como un 'sistema abstracto' ("le systéme abstrait"), y así tituló el capítulo 7 en el que incluye y explica extensamente esa definición. Pero Gladkij y Melchuk (1972: 94) reconocen abiertamente el fracaso de la aplicación de la lingüística matemática a las lenguas naturales: "...no podemos ofrecer al lector una exposición bien trabada de resultados precisos en lo tocante a la descripción de los lenguajes naturales empleando las gramática generativas de tal o cual clase. Tendremos que limitarnos a consideraciones de carácter general y a un reducido número de hechos conocidos".
} 
nitidez los fenómenos analizados y simplifican el tratamiento de los datos. Si la aplicación de las gramáticas generativas a las lenguas naturales pudiera ser discutible, no lo es la aplicación de la teoría de conjuntos. Tomando esta última como base, parece deducirse que la gramática de una lengua es una correspondencia definida entre dos conjuntos, uno de significantes y otro de significados. En matemáticas, la imagen de un elemento se representa como $\mathrm{f}(\mathrm{a})=\mathrm{b}$, siendo $b$ la imagen de $a$ en la correspondencia f: A 6 B definida por el conjunto A y por el conjunto B y, en ella, un elemento del conjunto inicial puede tener una imagen o varias en el conjunto final.

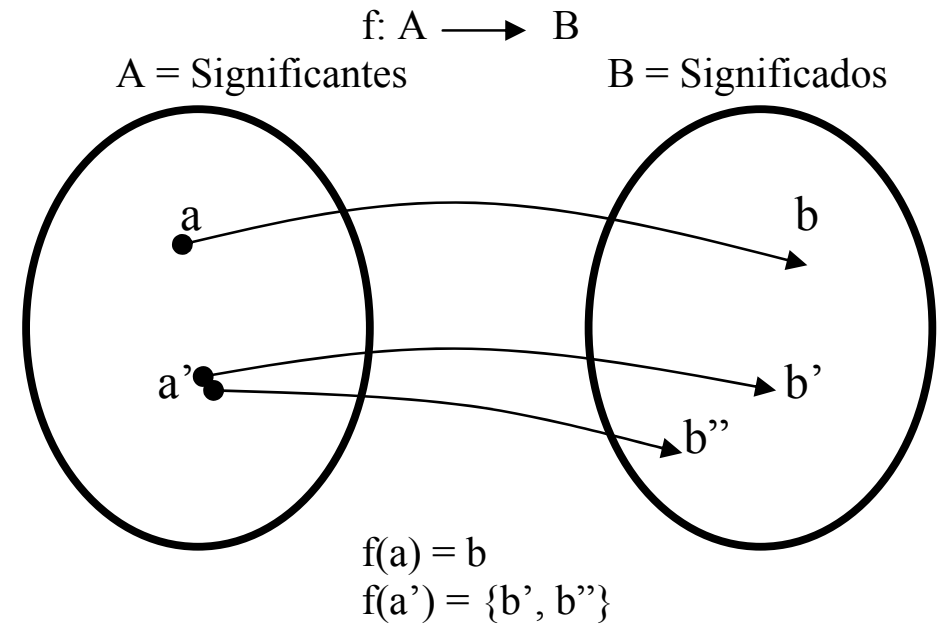

Ilustración 2. Correspondencia definida entre el conjunto de los significantes y el de los significados.

Todo elemento morfológico verbal y su función gramatical forman un par ordenado perteneciente a una correspondencia definida entre el conjunto de los elementos morfológicos verbales y el conjunto de las funciones gramaticales de una lengua. Este par ordenado se puede representar entonces igual que en la teoría de conjuntos. Por ejemplo, el sufijo de plural vasco $-z$ se representa como una igualdad $e_{m}{ }^{v}(P l)=-z$ con la función gramatical entre paréntesis porque es la imagen de la función gramatical de plural, y lo mismo se puede hacer con los demás elementos morfológicos. Así, el sufijo -te sería la imagen de dos funciones gramaticales distintas, la de plural de la $2^{\mathrm{a}}$ persona y la del modo potencial, que a su vez tendría dos imágenes distintas, la del sufijo -te y la del sufijo -ke. 


$$
\left.\begin{array}{c}
\mathrm{f}: \mathrm{F}_{\mathrm{g}} \longrightarrow \\
\mathrm{F}_{\mathrm{g}}=\text { Funciones gramaticales }
\end{array} \mathrm{fe}_{\mathrm{m}} \mathrm{e}_{\mathrm{m}}{ }^{\mathrm{v}}\right\}=\text { Elementos morfológicos }
$$

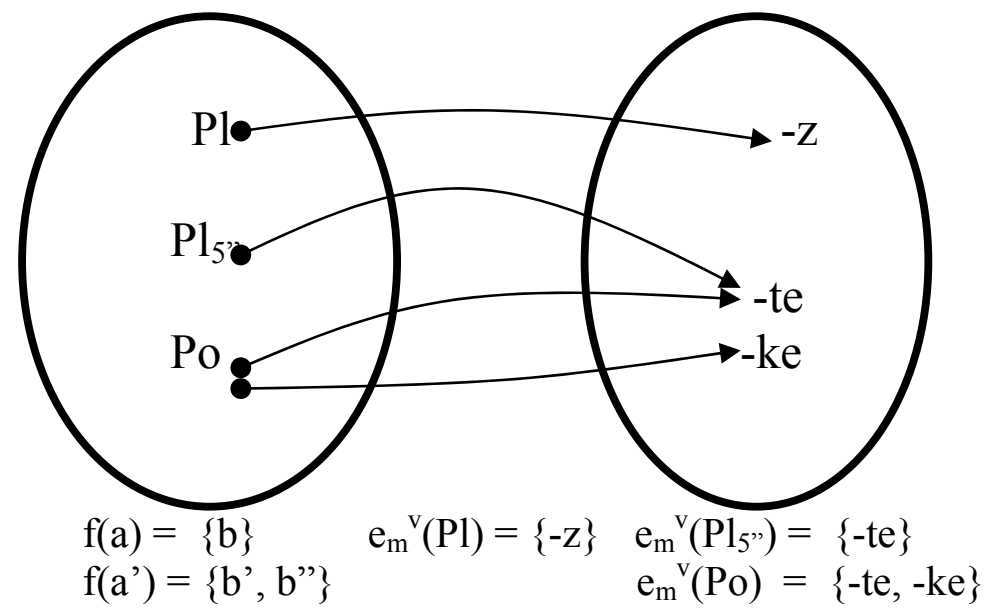

Ilustración 3. Correspondencia definida entre el conjunto de las funciones gramaticales y el de los elementos morfológicos de la lengua vasca.

Además, los significantes se combinan entre sí, dentro del mismo conjunto, en función de unas estructuras fonéticas, morfológicas o sintácticas que son relaciones binarias de orden total (RBOT) y lo mismo ocurre con los significados o las funciones gramaticales, que también definen unas relaciones binarias de orden total (RBOT) dentro del mismo conjunto $^{13}$. Ambos conjuntos, el de los significantes y el de los significados y funciones gramaticales, definen entre sí una correspondencia porque cada elemento del conjunto inicial tiene una imagen o varias en el conjunto final. Por ejemplo, la forma verbal $n-a-g o=$ 'yo estoy' se representaría por $\mathrm{N}_{1} \operatorname{PrR}$, donde $\mathrm{N}_{1}=n-, \operatorname{Pr}=-a-\mathrm{y} \mathrm{R}=-g o$.

\footnotetext{
${ }^{13}$ Una relación binaria $\mathrm{RB}$ en un conjunto $\mathrm{A}$ es una correspondencia $\mathrm{f}: \mathrm{A} \rightarrow \mathrm{A}$ definida dentro de ese mismo conjunto A. Es reflexiva si cualquiera que sea el elemento a del conjunto A, el par ordenado (a, a) verifica la relación. Es simétrica si, verificando el par $(\mathrm{a}, \mathrm{b})$ la relación, también la verifica su transpuesto (b, a). Es antisimétrica si, para todo par $(\mathrm{a}, \mathrm{b})$ y su transpuesto $(\mathrm{b}, \mathrm{a})$ que verifiquen la relación simultáneamente, es lícito inferir que $\mathrm{a}=\mathrm{b}$. Es transitiva si, verificando la relación los pares $(\mathrm{a}, \mathrm{b}) \mathrm{y}(\mathrm{b}, \mathrm{c})$, también la verifica el par $(\mathrm{a}, \mathrm{c})$. Es conexa si, siendo $\mathrm{a}=\mathrm{b}$ uno de los pares $(\mathrm{a}, \mathrm{b})$, el par $(\mathrm{b}, \mathrm{a})$ verifica la relación. Una relación binaria de orden $\mathrm{RBO}$ es toda relación binaria, reflexiva, antisimétrica y transitiva. Una relación binaria de orden total RBOT es toda relación binaria, reflexiva, antisimétrica, transitiva y conexa. Un conjunto totalmente ordenado es todo conjunto en el que se define una relación binaria de orden total y una cadena es toda parte totalmente ordenada de un conjunto ordenado.
} 


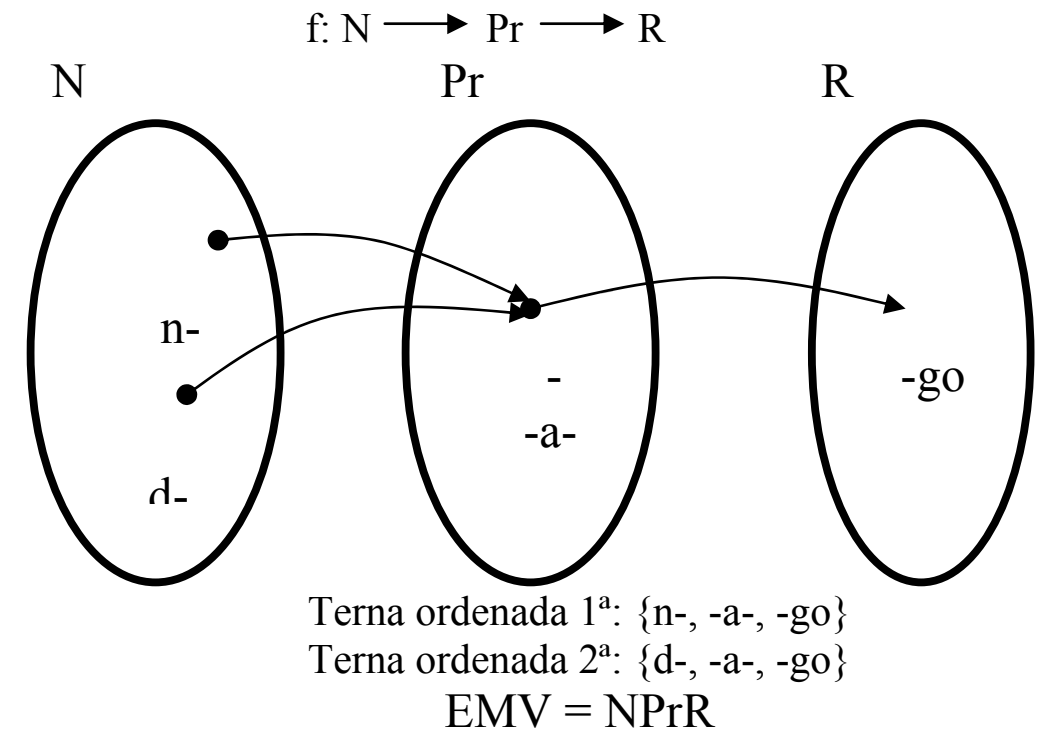

Ilustración 4. Correspondencia múltiple definida entre el conjunto de los prefijos personales, el de los infijos temporales y el de los lexemas verbales de la lengua vasca.

Cada uno de los elementos morfológicos de una misma forma verbal pertenecen a distintos subconjuntos que definen entre sí correspondencias cuyos elementos forman pares, ternas, cuádruplas o n-tuplas ordenadas que son las formas verbales o elementos léxicos que forman los sistemas morfológicos y se expresan formalmente en las estructuras morfológicas que simbólicamente los representan. Por ejemplo, la estructura morfológica verbal de $n-a-g o=$ 'estoy', $d-a-g o=$ 'está' sería NPrR.

Parece deducirse, por tanto, que la morfología se organiza como la teoría de conjuntos, esto es, como la identificación de unos elementos morfológicos agrupados en conjuntos de elementos que tienen una característica común: su función gramatical. El objetivo final de esta investigación lingüística es la obtención del proceso de evolución fonética (PEF) y del proceso de formación de la estructura morfológica verbal (PFEM), que también tienen naturaleza matemática al ser cadenas de cambios fonéticos y morfológicos que están definidas por una relación binaria de orden total (RBOT) y se pueden expresar, por tanto, por medio de fórmulas. Esta metodología matemática ha simplificado el tratamiento de los datos facilitando y haciendo imprescindible el empleo de símbolos y fórmulas, lo que ha facilitado la utilización de tablas, especialmente con flexiones completas, que han resultado especialmente adecuadas para la comparación de distintas flexiones y para la representación de los sistemas morfológicos verbales (SMV). En el análisis de la morfología verbal vasca, hemos ido de menor a mayor complejidad, comenzando por lo más simple, los elementos morfológicos verbales, y acabando por lo más complejo, las estructuras morfológicas verbales, en las que a su vez hemos comenzado por las más simples y hemos terminado por 
las más complejas. Esta metodología nos ha permitido identificar todos los elementos morfológicos verbales vascos, clasificarlos y conocer su origen y su cronología relativa.

\section{Aplicación de la Teoría de Conjuntos a la morfología verbal de la lengua vasca}

\subsection{Los elementos morfológicos verbales}

Ante las lagunas que presentan las clasificaciones existentes, hemos realizado una clasificación sistemática de todos elementos morfológicos verbales en la que, según sus funciones, pueden ser temporales, modales, personales o de plural. Como ya estableció Azkue (1905-1906, 1923-1925), se puede concluir que los elementos morfológicos temporales de presente y de pasado son las vocales $-a-\mathrm{y}-e-$, respectivamente ${ }^{14}$, habiéndose sumado posteriormente en este último tiempo el infijo $-n$ - y el sufijo $-n^{15}$ (Domene, 2007c).

Los elementos morfológicos modales diferencian los 22 modos verbales vascos y los personales corresponden a 7 personas en los prefijos y a 8 en los sufijos. Actualizando la clasificación de Azkue (1905-1906), pueden ser de nominativo, de ergativo y de dativo ${ }^{16}$.

\footnotetext{
${ }^{14}$ Las antiguas EMV de Presente y de Pasado fueron en su origen comunes a todos los dialectos pero, desde el punto de vista sincrónico, algunas de estas EMV son hoy formalmente distintas debido a la distinta evolución fonética que han sufrido en cada dialecto. Así, en la mayoría de los dialectos se mantiene la oposición -a-/-e(habiendo evolucionado - $e$ - a - $i$ - delante de /n/ en la mayoría de ellos), mientras que en algunos dialectos orientales la oposición es -e-/-a-. El infijo - $e$ - se ha utilizado también con valor de presente en los verbos trivalentes, como indicó Michelena en 1954 (1988: 795). El afijo -e- en la flexión tricasual $\mathrm{N}_{3} \mathrm{DE}_{3}$ de algunos verbos cabría atribuirlo a la función de diferenciarla fonéticamente de la $\mathrm{N}_{3} \mathrm{E}$ bicasual transitiva, e incluso de diferenciar las flexiones de $3^{\mathrm{a}}$ persona singular de Nominativo (con -e-) y Ergativo (con - $a$-) como indicaron Schuchardt (1893), Michelena (1954), Altube (1934), Lafon (1955) y Lakarra (1996), quienes han señalado el carácter morfológico de esta alternancia y Michelena señaló también su presencia en los textos más antiguos como prueba de antigüedad. "Refranes y Sentencias, según su sistema, diferencia dEroat de dAroat, eztEkian de eztAkian. Capanaga, dEigula de dAigula. Barrutia, eztEgizuen de eztAgizuen. Micoleta, dEysu de dAysu" (Irigoien 1997: 43). Sin embargo, el origen de este afijo - $e$ - en el grupo [-ia-] postulado por Schuchardt o en el grupo [-ai-] postulado por Lafon (ambos con el infijo indicador de dativo -i-) no cumple las leyes fonéticas vascas porque estos grupos fonéticos han evolucionado fonéticamente a $y-, d d-, d x-, x-, j-y z-$, pero nunca a -e- (Michelena, 1961: 167-177). Tanto el grupo [-ia-] como el grupo [-ai-] se han reducido normalmente a /i/, a /a/ o ha evolucionado a [ei], pero no a /e/ (Michelena, 1961: 102-106, 122-123).

${ }^{15}$ El antiguo adverbio da = 'ahora', identificado por Oregi (1974) y De Rijk $(1992,1995)$, originó el prefijo dapropio de la $3^{\circ}$ persona de presente, pero no el infijo - $a$ - en las demás personas, como han propuesto Trask (1977) y De Rijk (1992), porque no ha quedado ningún indicio de ello. El infijo de pasado - $e$ - se reforzó con el infijo - $n$ cuando se formaron las estructuras multicasuales para diferenciar las flexiones de $1^{\mathrm{a}}$ y $2^{\mathrm{a}}$ persona de ergativo de la $1^{\mathrm{a}}$ y $2^{\mathrm{a}}$ persona de la flexión de $3^{\mathrm{a}}$ persona de nominativo, que originalmente eran idénticas debido a la diferente estructura de esta última flexión. Ambos afijos de pasado se volvieron a reforzar con un tercero, el sufijo - $n$ (no an/-en como indicó Michelena) propio del relativo y más tarde del modo subjuntivo, que sólo en la flexión de $3^{\text {a }}$ persona singular de nominativo aparece como -an/-en por la presencia de una vocal epentética. Esta vocal se debe a la desaparición de una /n/ intervocálica, pero dicha /n/ no pertenecía a la raíz, como propuso Trask (1990), sino a un primer sufijo $-n$ tras el que se añadió el segundo sufijo $-n$ con una vocal epentética para diferenciar el pasado del infinitivo y del imperativo en la única flexión que carece de sufijo personal (por ejemplo, e-go- $n=$ 'estar', pero $e$ go-en < *e-go-n-en = ‘él/ella/ello estaba' en vizcaíno) (Domene, 2007c).

${ }_{16}$ Ante las dudas que han suscitado los afijos originales de la $2^{\mathrm{a}}$ persona singular masculino, hemos podido determinar que la consonante original de dichos afijos era $/ \mathrm{g} /$ en todos los dialectos, de manera que el prefijo original de dicha persona era $* g$-, el sufijo $*$-ga y el pronombre personal $* g i$. Esta $/ g /$ desapareció entre vocales y se ensordeció en posición final, como apuntó Michelena (1961). El prefijo $g$ - desapareció pronto y se sustituyó por
} 
La lengua vasca es, por ello, de tipo ergativo (tipo A de Trask, 1979), ya que sólo se marca el Sujeto de los verbos transitivos, mediante el caso ergativo, pero no el Sujeto de los verbos intransitivos ni el objeto directo de los transitivos, que constituyen el caso nominativo, caso absoluto o caso cero.

Los afijos de plural son modernos y todavía no se utilizan en algunas estructuras de algunas localidades más aisladas. La inexistencia de una clasificación de $\operatorname{los} \mathrm{e}_{\mathrm{m}}{ }^{\mathrm{v}}(\mathrm{Pl})$ nos ha obligado a realizarla. Tras el análisis de todos ellos, se puede concluir que los $\mathrm{e}_{\mathrm{m}}{ }^{\mathrm{v}}(\mathrm{Pl})$ pueden ser generales $(-z,-z-k i$ y $-z k-a)$, específicos de algunas personas, concretamente la $2^{\mathrm{a}}$ y la $3^{\mathrm{a}}$ de plural (-de/-e/-te y sus alófonos), o específicos de algunos verbos (ukan, izan, egon $)^{17}$.

el prefijo $h$ - en los dialectos septentrionales, como indicó Lafon (1943) a partir de los textos de Dechepare (1545) y Leiçarraga (1571). Como apuntó Trask (1995), el antiguo pronombre * gi se utilizó como sufijo derivativo $-g i>-k i$ (por ejemplo, eba-gi > eba-ki) y como indicador de dativo -ki-, ensordeciendo la oclusiva en ambos casos, y originó el indicador de alocutivo - $i$ - al desaparecer de la /g/intervocálica. Hemos podido determinar igualmente que en todos los dialectos el sufijo original de la $3^{\mathrm{a}}$ persona plural es - de. Sin embargo, el origen del prefijo $n$ - y del sufijo - da de $1^{\mathrm{a}}$ persona singular en un fonema $/ \mathrm{n}^{\mathrm{d}} /$ propuesto por Martinet (cit. por Michelena, 1961) es inaceptable. El prefijo cero $(1)$ de $3^{a}$ persona en la estructura de pasado del vizcaíno no es más moderno que el prefijo z- de los demás dialectos, como defendió Michelena (1964) basándose en los textos antiguos, sino más antiguo, como defendieron Schuchardt (1893), Azkue (1923-1925), Lafon (1943), Trask (1977), Gómez y Sainz (1995) y otros autores.

${ }^{17}$ Además es posible determinar el origen y la cronología relativa de cada uno de ellos. Los afijos generales son el sufijo $-z$ y sus compuestos. El sufijo $-z$ está en el origen de todos los sufijos de plural generales vascos, y al añadirle el indicador de dativo - $k i$ - delante de los sufijos personales, se formó el sufijo -z-ki, que luego se utilizó también en los verbos transitivos. El sufijo -z-ki más el sufijo -o de $3^{\mathrm{a}}$ persona singular de dativo (-z-ki-o) evolucionó fonéticamente al sufijo -z-ka y, después, a los sufijos -tza, -tze y -tzi en algunos dialectos. Los sufijos específicos de algunas personas son el sufijo - de y sus variantes y sirvieron originalmente para formar la flexión de $3^{\mathrm{a}}$ persona plural de ergativo y dativo al añadirse a la $3^{\mathrm{a}}$ singular. El sufijo -de evolucionó a $-e$ entre vocales y a -te detrás de sibilante, y de -e y -de surgieron todos los demás sufijos específicos de algunas personas (-i, -ai, -ei, -re, -die, -rie, be, -bai, -bei, -bie, -ea). Por analogía con la $3^{\mathrm{a}}$ persona plural existente hasta ese momento, se originó la nueva flexión de $2^{\mathrm{a}}$ persona plural añadiéndose el mismo sufijo -e a la $2^{\mathrm{a}}$ persona de respeto. Los sufijos específicos de algunos verbos son el sufijo -de, utilizado en el verbo egon (estar), y los propios de los dos verbos auxiliares, izan (ser) y ukan (haber), que utilizan el sufijo - ra y el infijo -it-, respectivamente. Ambos tienen su origen en un fenómeno muy común en los verbos auxiliares vascos como es la sustitución de las flexiones de algunas personas por las de otro verbo, concretamente de iraun (durar) en el verbo izan (ser) y de itu (tener) en el verbo ukan (tener). Se trata de un procedimiento arcaico de expresión del plural, que permitió la formación de la $3^{\text {a }}$ persona de plural de nominativo $\left(d\right.$-ira $=$ 'ellos/ellas son' y $d$-itu $=$ 'él/ella/ello los/las ha') y más tarde se extendió a las $1^{\text {a }}$ y $2^{\mathrm{a}}$ persona de plural (ga-ra y za-ra en el verbo izan, y ga-it-u y za-it-u en el verbo ukan). Después se generalizó el sufijo $-z$ en todos los demás verbos y en todas las personas de plural. El origen de todos los afijos de plural en un primitivo afijo *-ti propuesto por Schuchardt (1923) es inaceptable porque no cumple las leyes fonéticas vascas (Domene, 2007b). 
$\mathrm{e}_{\mathrm{m}}{ }^{\mathrm{v}}\left\{\begin{array}{l}\text { de tiempo }\left\{\begin{array}{l}\text { presente: }-a- \\ \text { pasado }\left\{\begin{array}{l}\mathrm{e}- \\ -n- \\ -n\end{array}\right.\end{array}\right. \\ \text { de modo: } 22 \text { modos } \\ \text { de persona: } 7 / 8 \text { personas } \\ \text { de plural }\left\{\begin{array}{l}\text { generales: } \\ \text { específicos de algunas personas }\left(2^{\mathrm{a}} \text { y } 3^{\mathrm{a}} \text { plural }\right):-d e>-e>-t e \\ \text { específicos de algunos verbos }(\text { ukan, izan, egon }):-i t-,-r a,-d e\end{array}\right.\end{array}\right.$

Esquema 2. Clasificación de los elementos morfológicos verbales de plural de la lengua vasca.

Se confirma la clasificación modo-temporal propuesta por Azkue (1923-1925), formada por 2 tiempos (presente y pasado) y 22 modos. La posterior clasificación bipartita de Lafon (1943) (formas verbales pertenecientes al grupo real y formas del grupo irreal), así como todas las clasificaciones que de ella se derivan (formas de presente y de no-presente, por ejemplo), tienen evidente voluntad didáctica porque sólo incluyen las formas modotemporales que presentan particularidades y, por tanto, no se forman mecánicamente a partir del tiempo presente y del pasado. Sin embargo, carecen de validez desde un punto de vista descriptivo y explicativo de la estructura morfológica verbal vasca, sobre todo si se considera desde un punto de vista diacrónico.

\subsection{Las estructuras morfológicas verbales}

\subsubsection{Definición y clasificación}

La metodología empleada nos ha permitido igualmente identificar las estructuras morfológicas verbales, clasificarlas y conocer su proceso de formación con todos los cambios morfológicos y fonéticos que han sufrido hasta llegar a su estado actual.

Hemos definido una estructura morfológica verbal (EMV) como una correspondencia múltiple definida entre los conjuntos de elementos morfológicos verbales de una lengua que tienen una misma característica, que es la función gramatical que representan, en el mismo orden que tienen en el sistema morfológico verbal (SMV) al que corresponden. Igual que los conjuntos, las hemos definido por extensión, enumerando todos los elementos de los conjuntos que incluyen, y por comprensión, enumerando sólo las características de esos conjuntos, o sea, la función gramatical que representan. Esta metodología matemática nos ha permitido utilizar una terminología que se puede expresar por medio de fórmulas y resulta más idónea y apta para ser utilizada en la estructura de cualquier otra lengua. Como apuntó Michelena (1987: 48), hemos confirmado que la estructura analítica vasca tiene un origen tardo-latino y la estructura sintética, por tanto, es la más antigua en la lengua vasca. 
Por ejemplo, la EMV unicasual vizcaína de egon (estar) definida por extensión es la siguiente:

EMV(Pr, egon ) vizcaína $=\left\{\begin{array}{l}n- \\ \mathrm{l} \\ \mathrm{d}- \\ \mathrm{g}- \\ \mathrm{z}- \\ \mathrm{z}- \\ \mathrm{d}-\end{array}\right\} \mathrm{H}\{-\mathrm{a}\} \mathrm{H}\{-\mathrm{go}\} \mathrm{H}\{-\mathrm{z}\}$ 4-6 $\mathrm{H}\{-\mathrm{e}\}$ 5"

$\operatorname{EMV}(\operatorname{Pr}$, egon $)=\{\mathrm{n}-, \mathrm{l}, \mathrm{d}-, \mathrm{g}-, \mathrm{z}-, \mathrm{z}-, \mathrm{d}-\} \mathrm{H}\{-\mathrm{a}-\} \mathrm{H}\{-\mathrm{go}\} \mathrm{H}\{-\mathrm{z}\}_{4-6} \mathrm{H}\{-\mathrm{e}\}_{5}$,

La EMV vizcaína de egon (estar) definida por comprehensión consiste en sustituir cada uno de los conjuntos que forman la EMV por sus características respectivas, que son sus funciones gramaticales:

$$
\operatorname{EMV}(\mathrm{Pr}, \text { egon })=\mathrm{NHPrHRHPl}_{4-6} \mathrm{HPl}_{5},=\mathrm{NPrRPl}_{4-6} \mathrm{Pl}_{5},
$$

La clasificación que proponemos se basa en los casos que contengan y las EMV ordenadas de menor a mayor complejidad. Las EMV vascas pueden ser sintéticas y analíticas, y estas últimas utilizan un verbo auxiliar con EMV sintética o analítica. Las sintéticas pueden ser acasuales o áptotas (R), si no incluyen ningún caso, sino sólo la raíz (R), como ocurre en los modos impersonales (Infinitivo/Participio y Gerundio) (por ejemplo, jo = 'pegar', e-rama- $n=$ 'llevar', $e$-torr $-i=$ 'venir, etc.); unicasuales o monóptotas $(\mathrm{NR}$ o $\mathrm{N}$ ), si sólo incluyen un caso, el Nominativo (N) (por ejemplo, $\boldsymbol{n}$ - $a$-tor = 'yo vengo'); bicasuales o díptotas, si incluyen dos casos, el Nominativo (N) y el Ergativo (E) en los verbos transitivos (NRE o NE) (por ejemplo, $\boldsymbol{d}$-a-rama-t = 'lo llevo yo') y el Nominativo (N) y el Dativo (D) en los intransitivos (NRD o ND) (por ejemplo, $\boldsymbol{n}$-a-tor-ki-o = 'yo le vengo a él'); y tricasuales o tríptotas ${ }^{18}$ (NRDE o NDE), si incluyen los tres casos posibles, el Nominativo (N), el Dativo (D) y el Ergativo (E) (por ejemplo, $\boldsymbol{d}$-a-gi-zu-t $=$ 'yo os lo hago' = 'lo hago a vos yo'). En la lengua vasca, cada una de estas EMV sintéticas puede ser a su vez alocutiva si le añade el caso Alocutivo (Al). Las EMV analíticas son las más modernas porque aparecieron en vasco por influencia de la EMV analítica tardo-latina ${ }^{19}$.

\footnotetext{
${ }^{18}$ Los términos "unicasual", "bicasual" y "tricasual" son preferibles a los tradicionales "unipersonal", "bipersonal" y "tripersonal" porque las EMV vascas están formadas por casos, y éstos a su vez por personas.

19 "In earlier centuries and up to the beginning of ours, researchers thought, almost unanimously, that the ancient Basque verb had only analytical ('periphrastic') forms, simple or synthetic foms being a corruption of those (Astarloa 1803, Bonaparte 1869, d'Abbadie \& Chaho 1836, Darrigol [1827], Harriet 1741, Inchauspe 1858, Larramendi 1729, among others). Oihenart (1638) is the most notable exception to this current of thought (see Gómez 1989: 361). Today, in contrast, there is universal agreement that the handful of verbs which have synthetic forms preserve a state of affairs which must have been much more general in older times. In fact, old texts presents a greater number of verbs with synthetic forms than are currently used. Neverless, the system of analytical forms
} 


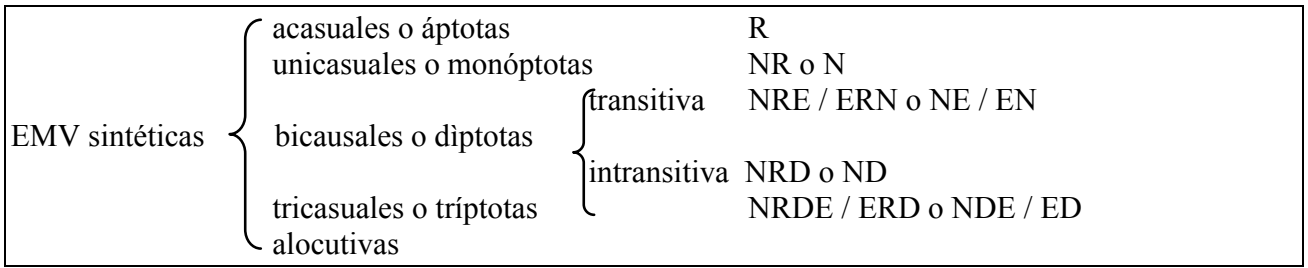

Esquema 3. Clasificación de los elementos morfológicos verbales de plural de la lengua vasca.

\begin{tabular}{|l|l|l|l|l|l|}
\hline $\begin{array}{l}\text { Clase de } \\
\text { EMV }\end{array}$ & Subclase de & Casos & $\begin{array}{l}\text { Denominación } \\
\text { tradicional }\end{array}$ & EMV(Pr) & General \\
\hline Acasual & & & R & & Vizcaína \\
\hline Unicasual & & NR & nor & NPrRPln & NPrRPln \\
\hline Bicasual & Transitiva & NRE & nor-nork & NPrRPlnE & NPrREPln \\
\hline & Intransitiva & NRD & nor-nori & $\begin{array}{l}\text { NPrRD0PlnD1 } \\
-6\end{array}$ & $\begin{array}{l}\text { NPrRD0D1- } \\
\text { 6Pln }\end{array}$ \\
\hline Tricasual & & NRDE & nor-nori-nork & NPrRPlnDE & NPrRDEPln \\
\hline
\end{tabular}

Tabla 2. Clases de EMV sintéticas vascas del Presente: EMV(Pr).

\subsubsection{La EMV acasual o áptota}

La estructura acasual o áptota es la propia de los modos impersonales y está formada por el radical (la raíz con el prefijo e-) más los afijos propios de cada uno de esos modos. La explicación global aportada en este trabajo, no sólo aclara el origen de los afijos y de las estructuras de los modos impersonales, sino también su cronología relativa y permite por tanto establecer la secuencia cronológica de todas las estructuras de las formas no personales. El infinitivo es el modo más antiguo y se caracterizaba por el prefijo $e$ - añadido

with an auxiliary appears as perfectly consolidated even in the erliest texts." (Gómez y Sainz, 1995: 237-238). Oihenart (1656) consideró la estructura sintética vasca como conjugación propia y a la analítica como impropia, y prácticamente todos los lingüistas del siglo XX han defendido la mayor antigüedad de la estructura sintética, sobre todo desde que René Lafon descubrió en su tesis doctoral Le système du verbe basque au XVI siècle (1943) que en los textos literarios del siglo XVI se empleaban 60 verbos con estructura sintética y que ese número se ha ido reduciendo de forma drástica hasta los dos únicos verbos (izan y ukan) que prácticamente la conservan en la actualidad. Michelena $(1964,1981)$ confirmó esta misma tesis, atribuyendo además el origen de la estructura analítica vasca a la influencia romance y enmarcándolo dentro de la tendencia general que se ha observado en otras lenguas europeas occidentales (por ejemplo, etorri $d a=$ cast. ant. es venido $=$ Fr. est venu $=\mathrm{Al}$. ist gekommen; egin $d u=$ cast. ha hecho $=$ Fr. a fait $=$ Al. hat gemacht; joango da = cast. ant. es de ir; egingo du = cast. ant. ha de hacer). En efecto, la EMV analítica se introdujo en vasco con la romanización para poder conjugar los numerosos verbos de origen latino, que se introdujeron en participio con el sufijo -tu, que tan productivo ha sido en la derivación vasca: "The suffix -tu is of Latin origin. Early Basque borrowed a very large number of verbs from Latin, and these were borrowed in the form of the perfective participle, which in most Latin verbs ended in $-t u(m)$ : Lat pensatu > Bq pentsatu 'think', Lat benedicatu > Bq bedeinkatu 'bless', and so on” (Trask, 1995: 211). 
a la raíz, el participio se formó como los adjetivos, al añadirle el sufijo -i al infinitivo, el sustantivo verbal se formó como los sustantivos, al añadirle el sufijo -te al infinitivo, y el gerundio fue el caso inesivo del sustantivo verbal, con el sufijo $-n$. Los modos impersonales primitivos son, por tanto, las siguientes:

\begin{tabular}{|l|l|l|}
\hline Modos impersonales & Sufijos & Ejemplos \\
\hline Infinitivo & & $*$ e-du, *e-iza, e-kar, *e-ma \\
\hline $\begin{array}{l}\text { Participio o adjetivo } \\
\text { verbal }\end{array}$ & $-\mathrm{i}$ & $*$ e-du-i, *e-iza-i, e-karr-i, *e-ma-i \\
\hline \multirow{2}{*}{ Sustantivo verbal } & -te & $*$ e-du-te, *e-iza-te, e-kar-te, e-ma-te \\
\cline { 2 - 3 } & -i-te & $*$ e-iza-i-te, e-ma-i-te \\
\hline $\begin{array}{l}\text { Gerundio o adverbio } \\
\text { verbal }\end{array}$ & -te-n & *e-du-te-n, *e-iza-te-n, e-kar-te-n, e-ma-te-n \\
\hline
\end{tabular}

Tabla 3. Los modos impersonales primitivos de la lengua vasca.

Sin embargo, el radical utilizado como infinitivo no sería antiguamente un sustantivo, como apuntó Trask $(1990,1995)$, sino que tendría su origen en la $3^{\text {a }}$ persona singular de nominativo del pasado, igual que ocurre en árabe. Por ello, el sufijo - $n$ no tiene su origen en la raíz de los verbos como igualmente apuntó Trask $(1990,1995)$, ya que no ha dejado ningún rastro en la estructura morfológica verbal, sino que estaría relacionado con el sufijo de pasado $-n$ al utilizarse la $3^{a}$ persona singular de pasado como infinitivo y, más tarde, también como participio. Al aparecer el sufijo $-n$ en la $3^{\mathrm{a}}$ persona singular del pasado de cada verbo, se incorporó también al infinitivo, igualándose de nuevo ambas formas verbales. Para diferenciarse, se añadió un nuevo sufijo $-n$ en la $3^{\mathrm{a}}$ persona singular del pasado, pero esta segunda vez necesitó una vocal epentética al añadirse detrás de $/ \mathrm{n} /$, desapareciendo después esta $/ \mathrm{n} /$ intervocálica (por ejemplo, $e$-go- $n=$ 'estar', pero $e$-go-en < *e-go-n-en = 'él/ella/ello estaba' en vizcaíno u occidental). Por lo tanto, la duplicación del sufijo - $n$ en esta flexión explica perfectamente todo el proceso ${ }^{20}$.

El sufijo -tu apareció como consecuencia de la romanización, al introducirse en vasco los verbos latinos en participio, y por tanto con sufijo -tu, y no en infinitivo (por ejemplo, $a u d i-t u(m)>a d i-t u=$ 'oído, oír'). Después, el sufijo -tu (convertido en -du trás $/ \mathrm{n} / \mathrm{y} / \mathrm{l} / \mathrm{s}$ ) se añadió a otras palabras para formar verbos (por ejemplo, hurbil-du = 'acercado, acercar', de hurbil = 'cerca'). Como fue el participio el que sirvió para nombrar estos verbos, se utilizó también como infinitivo, primero con los verbos de origen latino y después esto se generalizó a todos los verbos vascos, si bien de dos maneras diferentes: en los verbos con raíz acabada en consonante, el antiguo participio vasco con sufijo -i- se utilizó también como infinitivo (por ejemplo, ekarr-i = 'llevado, llevar'). En cambio, en los verbos con raíz

\footnotetext{
${ }^{20}$ La hipótesis contraria, esto es, la utilización del infinitivo con $e$ - y $-n$ en el pasado, señalada por Schuchardt (1893, 1923) y aceptada por Lafon (1943), Trask (1995), etc., supondría, primero, que el sufijo -n o -an/-en sería anterior a la formación de las estructuras multicasuales, lo cual es inaceptable, y segundo, que al añadirse los sufijos personales detrás de la raíz, se tendrían que haber adaptado fonéticamente a ella siguiendo las leyes fonéticas, lo cual es evidente que no ha ocurrido.
} 
acabada en vocal, fue el antiguo infinitivo (ya con sufijo - $n$ ) el que se utilizó también como participio (por ejemplo, ema- $n=$ 'dado, dar'). Esta utilización indistinta del infinitivo y el participio originó el fenómeno que hemos denominado convergencia infinitivo-participio (CIP).

Las demás estructuras morfológicas verbales son regulares en todos los verbos excepto en los auxiliares, en los que las irregularidades existentes se deben en su mayor parte a la utilización de otros verbos distintos en algunas de sus flexiones.

\subsubsection{La EMV inicasual o monóptota (N)}

La estructura unicasual o monóptota $(\mathrm{N})$ es la más simple de todas, es intransitiva y está formada por los prefijos personales, que indican el nominativo, los afijos de tiempo, la raíz y los sufijos de plural. El antiguo sufijo de plural -de se utilizó en lugar de -z en el verbo egon (estar) en todos los dialectos excepto el vizcaíno u occidental.

\begin{tabular}{|l|l|l|l|l|l|}
\hline & \multicolumn{2}{|c|}{ j-oa-n = 'ir' } & \multicolumn{3}{c|}{ e-go-n = 'estar' } \\
\hline $\mathrm{N}_{1}$ & n-oa & yo voy & n-a-go & n-a-go & yo estoy \\
$\mathrm{N}_{2}$ & oa & tú vas & a-go & a-go & tú estás \\
$\mathrm{N}_{3}$ & d-oa & él/ella/ello va & d-a-go & d-a-go & él/ella/ello está \\
$\mathrm{N}_{4}$ & g-oa-z & nosotros/as vamos & g-a-go-z & g-a- u-de & nosotros/as estamos \\
$\mathrm{N}_{5}$, & z-oa-z & vos vais & z-a-go-z & z-a- u-de & vos estáis \\
$\mathrm{N}_{5}$, & z-oa-z-te & vosotros/as vais & z-a-go-z-e & z-a- u-de-te & vosotros/as estáis \\
$\mathrm{N}_{6}$ & d-oa-z & ellos/ellas van & d-a-go-z & d-a- u-de & ellos/ellas están \\
\hline
\end{tabular}

Tabla 4. El sufijo de plural -z y el sufijo de plural -de en posición final en los SMV(N).

El verbo auxiliar intransitivo monovalente es izan (ser), pero se sustituyó por el antiguo adverbio $d a=$ 'ahora' en la $3^{\mathrm{a}}$ persona singular, como indicó De Rijk $(1992,1995)$, y se utilizó la $3^{\mathrm{a}}$ singular de iraun (durar) para expresar la $3^{\mathrm{a}}$ persona plural en época antigua, ya que ambas formas verbales son idénticas en todos los dialectos ( $d a=$ 'él/ella/ello es', dira $=$ 'ellos/ellas son') mientras que la $1^{\mathrm{a}}$ y $2^{\mathrm{a}}$ personas son diversas (gara / gare / gera / gira / gra = 'nosotros/as somos', por ejemplo). Más tarde, la sustitución de izan por iraun también se produjo en la $1^{\mathrm{a}}$ y $2^{\mathrm{a}}$ plural de la mayoría de los dialectos debido a la pluralización pleonástica (PP), haciendo la raíz de iraun las veces de un sufijo de plural -ra tras la reducción del diptongo [au] (ga-ra y za-ra en el verbo izan). Este procedimiento arcaico de expresión del plural permitió la formación de la $3^{\mathrm{a}}$ persona de plural de nominativo y más tarde se extendió a las $1^{\mathrm{a}}$ y $2^{\mathrm{a}}$ persona de plural. Después se generalizó el sufijo $-z$ en todos los demás verbos y en todas las personas de plural. 


\begin{tabular}{|l|l|l|l|l|l|l|l|}
\hline & Original & \multicolumn{1}{c|}{ V } & \multicolumn{1}{c|}{ L } & \multicolumn{1}{c|}{ G } & \multicolumn{1}{c|}{ BN } & \multicolumn{1}{c|}{ R y Sal. } & Significado \\
\hline $\mathrm{N}_{1}$ & $*$ n-a-iza & n-a-x & n-a-iz & n-a-iz & n- -iz & n- -iz & yo soy \\
$\mathrm{N}_{2}$ & $*$ h-a-iza & a-x & h-a-iz & a-iz & h- -iz & h- -iz & tú eres \\
$\mathrm{N}_{3}$ & $*$ d-a-iza & d-a & d-a & d-a & d-a & d-a & él/ella/ello es \\
$\mathrm{N}_{4}$ & $*$ g-a-iza & g-a-ra & g-a-re & g-e-ra & g-i-ra & g- -ra & nosotros/as somos \\
$\mathrm{N}_{5}$, & $*$ z-a-iza & z-a-ra & z-a-re & z-e-ra & z-i-ra & z- -ra & vos sois \\
$\mathrm{N}_{5}$, & $*$ z-a-iza & z-a-ri-e & z-a-re-te & z-e-ra-te & z-i-ra-de & z- -re-i & vosotros/as sois \\
$\mathrm{N}_{6}$ & $*$ d-a-iza & d-i-ra & d-i-re & d-i-ra & d-i-ra & d- -ra & ellos/ellas son \\
\hline
\end{tabular}

Tabla 5. SMV(N) antiguo y sustituido del presente de indicativo de izan = 'ser'.

Sin embargo, en los dialectos más extremos (vizcaíno occidental y roncalés), no se ha llegado a producir la pluralización pleonástica en la $1^{\mathrm{a}}$ y $2^{\mathrm{a}}$ plural del pasado (gintzan / gintzen $=$ 'nosotros/as somos') o bien se añadió el sufijo de plural $-z$ como en los demás verbos (gintza-z-an = 'nosotros/as somos').

\begin{tabular}{|c|c|c|c|c|c|}
\hline $\mathrm{Pe}$ & \multicolumn{2}{|c|}{ Sustitución en $3^{\mathrm{a}}$ plural } & \multicolumn{2}{|c|}{ Sustitución en $1^{\mathrm{a}}, 2^{\mathrm{a}}$ y $3^{\mathrm{a}}$ plural } & \\
\hline$\overline{\mathrm{N}_{1}}$ & n-i-n-tza- -n & n-i-n-tze- -n & n-i-n-tza- -n & n-i-n-tze- -n & yo soy \\
\hline $\mathrm{N}_{2}$ & i-n-tza- -n & i-n-tze- -n & i-n-tza- -n & i-n-tze- -n & tú eres \\
\hline $\mathrm{N}_{3}$ & z-i-n-tza- -n & z-i-n-tze- -n & z-i-n-tza- -n & z-i-n-tze- -n & él/ella/ello es \\
\hline $\mathrm{N}_{4}$ & g-i-n-tza- -n & g-i-n-tze- -n & $g-i-\tilde{n}-a--n$ & g-i-ñ- e - -n & nosotros/as somos \\
\hline $\mathrm{N}_{5}$ & z-i-n-tza- -n & z-i-n-tze- -n & $z-i-\tilde{n}-a--n$ & $z-i-\tilde{n}-e-\quad-n$ & vos sois \\
\hline $\mathrm{N}_{5}$ & z-i-n-tz -e-n & $z-i-n-t z e-i-n$ & $z-i-\tilde{n}-i \quad-e-n$ & $z-i-\tilde{n}-$ e -te-n & vosotros/as sois \\
\hline $\mathrm{N}_{6}$ & $z-i-\quad-r a \quad-n$ & $z-i-\quad-r e \quad-n$ & $\mathrm{z}-\mathrm{i}-\mathrm{-ra} \quad-\mathrm{n}$ & z-i- -re & ellos/ellas son \\
\hline
\end{tabular}

Tabla 6. Sustitución de las primitivas formas verbales del pasado de izan = 'ser' por las actuales.

\subsubsection{La EMV bicasual o díptota transitiva (NE)}

La estructura bicasual o díptota transitiva (NE) se formó al añadirle los sufijos de ergativo a la primitiva estructura unicasual transitiva, que se ha conservado en la flexión $\mathrm{NE}_{3} \mathrm{y}$, con su significado original, en la flexión $\mathrm{EN}_{3}$ del pasado. El verbo auxiliar transitivo bivalente es ukan, que sólo en vizcaíno occidental es regular con los demás verbos al presentar el sufijo de plural $-z$.

\begin{tabular}{|l|l|l|l|l|}
\hline & \multicolumn{2}{|c|}{ presente } & \multicolumn{2}{c|}{ pasado } \\
\hline $\mathrm{N}_{1} \mathrm{E}_{3}$ & n-a-u & (él/ella/ello) me ha & n-e- - b- - -an & (él/ella/ello) me había \\
$\mathrm{N}_{2} \mathrm{E}_{3}$ & a-u & (él/ella/ello) te ha & e- - u- - -an & (él/ella/ello) te había \\
$\mathrm{N}_{3} \mathrm{E}_{3}$ & d-a-u & (él/ella/ello) lo/la ha & e- - b- - -an & (él/ella/ello) lo/la había \\
$\mathrm{N}_{4} \mathrm{E}_{3}$ & g-a-u-z & (él/ella/ello) nos ha & g-e-n-du-z- -an & (él/ella/ello) nos había \\
$\mathrm{N}_{5} \mathrm{E}_{3}$ & z-a-u-z & (él/ella/ello) os ha & z-e-n-du-z- -an & (él/ella/ello) os había \\
$\mathrm{N}_{5} \mathrm{E}_{3}$ & z-a-u-z-e & (él/ella/ello) os ha & z-e-n-du-z-e- n & (él/ella/ello) os había \\
$\mathrm{N}_{6} \mathrm{E}_{3}$ & d-a-u-z & (él/ella/ello) los/las ha & e- -ba-z- -an & (él/ella/ello) los/las había \\
\hline
\end{tabular}

Tabla 7. El sufijo de plural -z en posición final en el SMV(NE) vizcaíno u occidental.

Sin embargo, en todos los demás dialectos y como un procedimiento arcaico de expresión del plural, se utilizó la $3^{\mathrm{a}}$ persona singular del verbo itu para expresar la $3^{\mathrm{a}}$ 
persona plural de nominativo de ukan, originándose el nuevo infijo de plural -it- por falso análisis al identificar la /u/ con la raíz de ukan ( $d$-itu = 'él/ella/ello los/las tiene' se convirtió en $d$-it- $u=$ 'él/ella/ello los/las ha'). En algunos dialectos esto ocurrió más tarde, una vez generalizado el uso del sufijo de plural $-z$, y la flexión utilizada no fue la $\mathrm{N}_{3} \mathrm{E}$ de itu, sino la más moderna $\mathrm{N}_{6} \mathrm{E}$, originándose así la duplicación pleonástica de plural (DPP). Después, el nuevo infijo de plural -it- se extendió a la $1^{\mathrm{a}}$ y $2^{\mathrm{a}}$ persona de plural, que conservaron la /a/ del infijo de presente (ga-it-u y za-it-u en el verbo ukan) (Domene, 2007b).

\begin{tabular}{|c|c|c|c|c|c|c|}
\hline & \multicolumn{3}{|c|}{ presente } & \multicolumn{3}{|c|}{ pasado } \\
\hline & $\begin{array}{l}\sin \text { DPP } \\
\text { (Aizarna) }\end{array}$ & $\begin{array}{l}\text { con DPP mod. } \\
\text { (Hernani) }\end{array}$ & $\begin{array}{l}\text { con DPP ant. } \\
\text { (occidental) }\end{array}$ & & $\begin{array}{l}\text { sin PP } \\
\text { (Aizarna) }\end{array}$ & sin PP (Zaldibia) \\
\hline $\mathrm{N}_{1} \mathrm{E}_{6}$ & n-a- -u-e & n-a- -u- -te & n-a- -u-e & $\mathrm{N}_{1} \mathrm{E}_{3}$ & n-i-ñ- -u- - n & n-i-ñ- -u- \\
\hline $\mathrm{N}_{2} \mathrm{E}_{6}$ & a- -u-e & a- -u- -te & a- -u-e & $\mathrm{N}_{2} \mathrm{E}_{3}$ & $\mathrm{i}-\tilde{n}--\mathrm{u}--\mathrm{n}$ & i-ñ- -u- \\
\hline $\mathrm{N}_{3} \mathrm{E}_{6}$ & d-e- -u-e & d- $\quad-$ u- -te & d-e- -u-e & $\mathrm{N}_{3} \mathrm{E}_{3}$ & -u- -an & -ô- \\
\hline $\mathrm{N}_{4} \mathrm{E}_{6}$ & g-a-it-u-e & g-a-it-u-z-te & g-a-it-u-e-z & $\mathrm{N}_{4} \mathrm{E}_{3}$ & g-i-ñ- -u- - n & g-i-ñ- -u-z- -en \\
\hline $\mathrm{N}_{5}, \mathrm{E}_{6}$ & z-a-it-u-e & z-a-it-u-z-te & z-a-it-u-e-z & $\mathrm{N}_{5^{\prime}} \mathrm{E}_{3}$ & $\mathrm{z}-\mathrm{i}-\tilde{n}-{ }^{-u}-\quad-n$ & z-i-ñ- -u-z- -en \\
\hline $\mathrm{N}_{5^{\prime \prime}} \mathrm{E}_{6}$ & z-a-it-u-e & z-a-it-u-z-te-te & z-a-it-u-e-z & $\mathrm{N}_{5^{n}} \mathrm{E}_{3}$ & $z-i-\tilde{n}-\quad-u-e-n$ & z-i-ñ- -u-z-te- n \\
\hline $\mathrm{N}_{6} \mathrm{E}_{6}$ & d- -it-u-e & d- -it-u-z-te & d- -it-u-e-z & $\mathrm{N}_{6} \mathrm{E}_{3}$ & $z-\quad-i \bar{t}-u--n$ & $z-\quad-i \bar{t}-u-$ \\
\hline
\end{tabular}

Tabla 8. SMV(NE 6$)$ actual con infijo de plural -it-.

Sin embargo, en estas dos flexiones no se añadió -it- en algunos dialectos como el occidental de Léniz) y, en el pasado de otros (una parte del guipuzcoano o central), no se añadió -it- sino -z. El infijo de plural -it- no existió nunca, por tanto, en la estructura unicasual de izan y no pudo originar el sufijo de plural -ra como postuló Schuchardt $(1893)^{21}$.

${ }^{21}$ H. Schuchardt $(1893,32)$ fue el primer lingüista que intentó explicar el origen de tan misterioso alomorfo y consideró que -it-, lo mismo que -z, procedía de un antiguo sufijo de plural *-ti, reconstruido y no documentado, que dio origen también a los sufijos $-t e,-d e \mathrm{y}-e, \mathrm{y}$ a todas sus variantes fonéticas, mediante los cambios fonéticos $i$ $>e, t>d$ y $d>\wp$; en definitiva, mediante el proceso de evolución fonética $*-t i>-t e>-d e>-e$, aunque también dio origen al afijo -it- e, incluso, al sufijo $-z$ y al infijo -ir- de las personas de plural del presente del verbo izan monovalente. El cambio fonético $d>\imath$ cumple las leyes fonéticas (Michelena, 1961: 226), pero $i>e$ y $t>d$ no las cumplen porque /i/ sólo se abre en /e/ ante /r/ más consonante (Michelena, 1961: 62) y porque las oclusivas sordas no se sonorizan entre vocales (Michelena, 1961: 234). También procedían de ese hipotético *-ti, según él, el sufijo - $z$ y el supuesto infijo -ir- del verbo izan ( $g$-ir- $a=$ 'nosotros somos'). El desconocimiento de las leyes fonéticas de la lengua vasca en aquel momento le llevó a formular tales hipótesis.A pesar de ello, G. Lacombe (1936: 182) consideró confirmada la hipótesis de Schuchardt sobre la existencia de un primitivo afijo *-ti por la variante ditio de Ulzama, que analiza $d$-i-ti-o ('él/ella/ello se los/las ha a él/ella/ello') y procedería de ima fpr,a verbal $* d-a-t i-u$. R. Lafon (1943: 415) rechazó que $d$-it-u proceda de *d-a-ti-u y postuló una forma verbal *d-a-it-du, de la cual procedería *d-a-it-u y, de esta última, la actual $d-i t-u$. Sin embargo, esa variante ditio, se explica mucho mejor por la adición del infijo -it- a $d$-i-o = 'él/ella/ello se lo/la ha a él/ella/ello' por analogía con el verbo ukan = 'haber, tener', por lo que el análisis correcto es $d-i t-i-o$, y no $d-i-t i-o$ (Domene, 2005: Anexo X, 106-122).Posteriormente, R. Lafon $(1952,73)$ sugirió, al comentar la forma ytuten del infinitivo/gerundio de ukan del ${ }^{\circ} 375$ de los Refranes y Sentencias (dakianac bildur ytuten dadique giçon yzaiten = 'el que sabe tener miedo, sabe ser hombre'), que la antigua raíz del verbo ukan podría ser tu en vez de $d u$, de tal manera que ytuten = 'tener' se analizaría i-tu-ten, aunque esto sólo lo considera una simple posibilidad: "on semble avoir faire un sustantif verbal i-tu-ten, d'un racine tu. Mais de cette forme unique il serait imprudent de tirer une conclusion ferme" (Lafon: 1952, 73). J. Heath (1977) se limitó a considerar que el afijo -it- procede de un primitivo afijo *-iC- formado por una /i/ seguida de una 


\begin{tabular}{|c|c|c|c|c|c|}
\hline & \multicolumn{2}{|c|}{ Presente } & \multicolumn{3}{|c|}{ Pasado } \\
\hline & V de Léniz & & G de Aizarna & G de Zaldibia & \\
\hline $\mathrm{N}_{1} \mathrm{E}_{3}$ & $n-a--u$ & (él) me ha & $n-i-\tilde{n}--u-\quad n$ & n-i-ñ- -u- & (él) me había \\
\hline $\mathrm{N}_{2} \mathrm{E}_{3}$ & $a--u$ & (él) te ha & $\mathrm{i}-\tilde{n}--\mathrm{u}-\quad-\mathrm{n}$ & $\mathrm{i}-\tilde{n}-\quad-u-$ & (él) te había \\
\hline $\mathrm{N}_{3} \mathrm{E}_{3}$ & $d-a--u$ & (él) lo ha & $\mathrm{z}-\quad-\mathrm{u}-\mathrm{-an}$ & -ô- & (él) lo había \\
\hline $\mathrm{N}_{4} \mathrm{E}_{3}$ & g-a- -u & (él) nos ha & $g-i-\tilde{n}--u-\quad n$ & g-i-ñ- -u-z- -en & (él) nos había \\
\hline $\mathrm{N}_{5}, \mathrm{E}_{3}$ & $z-a--u$ & (él) os ha & $\mathrm{z}-\mathrm{i}-\tilde{n}-\quad-\mathrm{u}-\quad-\mathrm{n}$ & $z-i-\tilde{n}-\quad-u-z-\quad$-en & (él) os había \\
\hline $\mathrm{N}_{5 "} \mathrm{E}_{3}$ & $z-a--u$ & (él) os ha & $z-i-\tilde{n}-\quad-u-e-n$ & $z-i-\tilde{n}-\quad-u-z-t e-n$ & (él) os había \\
\hline $\mathrm{N}_{6} \mathrm{E}_{3}$ & d- -it-u & (él) los ha & $z-\quad-i \bar{t}-u--n$ & $-i \bar{t}-u-$ & (él) los había \\
\hline
\end{tabular}

Tabla 9. $\mathrm{SMV}\left(\mathrm{NE}_{6}\right)$ actual con infijo de plural -it-.

Como ya demostró Michelena (1982) y se acepta de forma generalizada (Trask, 1979; Brettschneider, 1979; Rotaetxe, 1978a, 1978b, 1980), la lengua vasca es ergativa ${ }^{22}$. En cambio, se puede establecer que, el fenómeno de la ergatividad surgió al distinguir en los verbos transitivos el agente del paciente, esto es, el sujeto transitivo del objeto directo, que hasta ese momento no se distinguían formalmente. Se marcó así el sujeto transitivo con el caso ergativo (en otras lenguas aglutinantes se utilizaron otros casos como el dativo, el locativo o el instrumental) y la consecuencia indirecta fue que el sujeto de los verbos intransitivos y el objeto directo de los transitivos, que quedaron sin marcar, acabaron por coincidir en el mismo caso (nominativo, caso cero o caso absoluto) ${ }^{23}$. La consecuencia fue la asimilación morfológica de los pronombres y prefijos personales de los verbos transitivos

consonante desconocida, probablemente una oclusiva, que seguida de la /d/ de la raíz -du se convirtió en /t/ como consecuencia de la ley fonética según la cual, en el choque de dos oclusivas cualesquiera, "el resultado es el enmudecimiento de la implosiva con ensordecimiento de la explosiva" (Michelena, 1961: 345). En este caso concreto, la consonante que se ha enmudecido es la del afijo $*_{-i C}$-, cualquiera que sea el valor de la oclusiva $\mathrm{C}$, y la que se ha ensordecido es la /d/ de la raíz - $d u$. Pero esto es como no decir nada. Esta hipótesis no aclara realmente el origen del afijo -it- y, lo que es más importante, no explica por qué existe sólo en el verbo ukan y no existe en ningún otro verbo porque. De ser cierta, el primitivo afijo *-iC- se debería haber utilizado también en los demás verbos. Pero, en ellos, la enigmática consonante representada por C habría evolucionado de forma diversa en la conjugación de los verbos con raíz empezada por consonante, dependiendo de la consonante inicial de la raíz de cada verbo, y se habría conservado intacta en los verbos de los verbos con raíz empezada por vocal. Y, sin embargo, no ha ocurrido así. Por lo tanto, con esta hipótesis, el problema sigue donde estaba y seguimos sin conocer el origen del afijo -it-.El origen del afijo de plural -it-, propio del verbo ukan, en el antiguo verbo itu = 'tener', al ser utilizada su flexión de $3^{\mathrm{a}}$ persona singular de nominativo como $3^{\mathrm{a}}$ persona singular de nominativo de ukan como una forma arcaica de expresión del plural, explica el origen de este enigmático afijo de plural vasco y todas las variantes dialectales de las flexiones de plural de nominativo del verbo ukan sin que existan contradicciones y cumpliendo siempre las leyes fonéticas vascas (Domene, 2007b).

${ }^{22}$ La tradición hasta entonces para explicar el fenómeno de la ergatividad era la "teoría pasiva", según la cual el verbo transitivo vasco estaría realmente en voz pasiva y, por eso, el objeto directo va en nominativo, igual que el sujeto de los verbos intransitivos. El sujeto de los verbos transitivos, en cambio, sería el complemento agente. La "teoría pasiva" del verbo vasco fue seguida por prácticamente todos los lingüistas Uhlenbeck, 1922; Lafon, 1943, Yrizar, 1947, 1981; etc.) desde que la expusiera Schuchardt (1893), e incluso fue tenida en cuenta por Bakker (1984) más recientemente. Martinet ya indicó que, en las lenguas de tipo ergativo, no se puede hablar en sentido estricto de voz activa ni de voz pasiva, sino que el verbo es neutro en lo que a la voz se refiere: "Comme toutefois les faits linguistiques ne valent que par opposition, le linguistes répugnent à parler d'un passif lá où il n'est pas en opposition avec un actif' (Martinet 1962: 79).

${ }^{23}$ En las lenguas flexivas, en cambio, lo que se marcó normalmente fue el objeto directo mediante el caso acusativo. 
con los pronombres y prefijos personales de los intransitivos y, consiguientemente, de la flexión $\mathrm{NE}_{3}$ de los verbos transitivos con la flexión $\mathrm{N}$ de los intransitivos. Esa es la razón por la que ambas comparten el infijo de pasado - $n$ - y el sufijo de plural -z/-zki- en las mismas personas, y lo mismo ocurre entre las estructuras NE y ND (Domene, 2007a, II: 362-389).

\author{
Sujeto Intransitivo $\square$ Sujeto Transitivo \\ Sujeto Intransitivo $=$ Objeto Directo \\ caso ergativo $=$ sujeto transitivo \\ caso nominativo $=$ sujeto intransitivo $=$ objeto directo
}

Las diversas hipótesis que se han ofrecido para explicar la distinta estructura de las flexiones de $3^{\mathrm{a}}$ persona de nominativo del pasado, $\mathrm{EN}_{3}$ en vez de $\mathrm{N}_{3} \mathrm{E}$, como son la "Antipasivización" de J. Heath (1976, 1977), la "ergatividad parcial" o "split ergativity" de R. L. Trask $(1977,1979)$ o el "desplazamiento de ergativo" de Itziar Laka (1988, 1993a, 1993b), no explican satisfactoriamente esta irregularidad ya que pretenden explicar un fenómeno morfológico con parámetros sintácticos.

\begin{tabular}{|l|l|l|l|l|l|}
\hline \multicolumn{4}{|c|}{ Flexión $\mathrm{N}_{3} \mathrm{E}$ (hura) } & \multicolumn{3}{c|}{ Flexión $\mathrm{NE}_{3}$ (hark) } \\
\hline $\mathrm{E}_{1}{ }_{1} \mathrm{~N}^{\prime}{ }_{3}$ & n-e-n-gi- -an & yo (lo) hacía & $\mathrm{N}_{1} \mathrm{E}_{3}$ & n-e-n-gi- -an & (él) me hacía \\
$\mathrm{E}_{2} \mathrm{~N}_{3}{ }_{3}$ & e-n-gi- -an & tú (lo) hacías & $\mathrm{N}_{2} \mathrm{E}_{3}$ & e-n-gi- -an & (él) te hacía \\
$\mathrm{E}_{3}{ }_{3} \mathrm{~N}_{3}{ }_{3}$ & e- -gi- -an & (él) (lo) hacía & $\mathrm{N}_{3} \mathrm{E}_{3}$ & e- -gi- -an & (él) lo hacía \\
$\mathrm{E}_{4}{ }_{4} \mathrm{~N}_{3}{ }_{3}$ & g-e-n-gi- -an & nosotros (lo) hacíamos & $\mathrm{N}_{4} \mathrm{E}_{3}$ & g-e-n-gi- -z-an & (él) nos hacía \\
$\mathrm{E}_{5}{ }_{5} \mathrm{~N}_{3}{ }_{3}$ & z-e-n-gi- -an & vos (lo) hacíais & $\mathrm{N}_{5} \mathrm{E}_{3}$ & z-e-n-gi- -z-an & (él) os hacía \\
$\mathrm{E}_{5}{ }_{5} \mathrm{~N}^{\prime}{ }_{3}$ & z-e-n-gi-e- n & vosotros (lo) hacíais & $\mathrm{N}_{5} \mathrm{E}_{3}$ & z-e-n-gi-e-z-an & (él) os hacía \\
$\mathrm{E}_{6}{ }_{6} \mathrm{~N}_{3}{ }_{3}$ & e- -gi-e- $\mathrm{n}$ & ellos (lo) hacían & $\mathrm{N}_{6} \mathrm{E}_{3}$ & e- -gi-e-z-an & (él) los hacía \\
\hline
\end{tabular}

Tabla 10. EMV(NE) vizcaína del pasado de egin = 'hacer'.

Su explicación hay que buscarla en el ámbito de la morfología, y tuvo la finalidad de distinguir la flexión $\mathrm{N}_{3} \mathrm{E}$ del pasado de la $\mathrm{N}_{3} \mathrm{E}$ del imperativo, que de lo contrario se habrían confundido porque la $3^{\mathrm{a}}$ persona carecía de afijos personales. La flexión $\mathrm{NE}_{3}$ del pasado se diferenció entonces de la $\mathrm{E}_{3} \mathrm{~N}$ añadiendo el infijo - $n$ - en las flexiones de $1^{\mathrm{a}}$ y $2^{\mathrm{a}}$ persona, aunque posteriormente también se añadió - $n$ - en las personas de plural de la flexión $\mathrm{E}_{3} \mathrm{~N}$. En el presente, en cambio, se añadió el antiguo adverbio $* d a=$ 'ahora' en la flexión $\mathrm{N}_{3} \mathrm{E}$. La estructura $\mathrm{EN}_{3}$ de $3^{\mathrm{a}}$ persona del pasado, que es análoga a la unicasual intransitiva actual, sería entonces la primitiva estructura transitiva de la lengua vasca. 


\begin{tabular}{|l|l|r|l|l|l|l|}
\hline \multicolumn{3}{|c|}{ Flexión $\mathrm{N}_{3} \mathrm{E}$ (hura) de pasado (reconstruida y actual). } & \multicolumn{3}{|c|}{ Flexión $\mathrm{N}_{3} \mathrm{E}$ (hura) de imperativo. } \\
\hline $\mathrm{E}_{1} \mathrm{~N}_{3}$ & $*$ e-gi-t & n-e-n-gi- -an & yo (lo) hacía & $\mathrm{N}_{3} \mathrm{E}_{1}$ & & \\
$\mathrm{E}_{2} \mathrm{~N}_{3}$ & $*$ e-gi-k & e-n-gi- -an & tú (lo) hacías & $\mathrm{N}_{3} \mathrm{E}_{2^{\prime}}$ & e-gi-k & haz(lo) tú \\
$\mathrm{E}_{2} \mathrm{~N}_{3}$ & $*$ e-gi-n & e-n-gi- -an & tú (lo) hacías & $\mathrm{N}_{3} \mathrm{E}_{2 "}$ & e-gi-n & haz(lo) tú \\
$\mathrm{E}_{3} \mathrm{~N}_{3}$ & $*$ e-gi & e- -gi- -an & (él) (lo) hacía & $\mathrm{N}_{3} \mathrm{E}_{3}$ & b-e-gi & hága(lo) él \\
$\mathrm{E}_{4} \mathrm{~N}_{3}$ & $*$ e-gi-gu & g-e-n-gi- -an & nos. (lo) hacíamos & $\mathrm{N}_{3} \mathrm{E}_{4}$ & & \\
$\mathrm{E}_{5} \mathrm{~N}_{3}$ & $*$ e-gi-zu & z-e-n-gi- -an & vos (lo) hacíais & $\mathrm{N}_{3} \mathrm{E}_{5^{\prime}}$ & e-gi-zu & haced(lo) vos \\
$\mathrm{E}_{5} \mathrm{~N}_{3}$ & $*$ e-gi-zu-e & z-e-n-gi-e- $\mathrm{n}$ & vos. (lo) hacíais & $\mathrm{N}_{3} \mathrm{E}_{5 "}$ & e-gi-zu-e & haced(lo) vos. \\
$\mathrm{E}_{6} \mathrm{~N}_{3}$ & $*$ e-gi-e & e- -gi-e- $\mathrm{n}$ & ellos (lo) hacían & $\mathrm{N}_{3} \mathrm{E}_{6}$ & b-e-gi-e & hágan(lo) ellos \\
\hline
\end{tabular}

Tabla 11. $\operatorname{EMV}\left(\mathrm{E}_{3} \mathrm{~N}\right)$ de pasado de egin = 'hacer' y $\operatorname{EMV}\left(\mathrm{NE}_{3}\right)$ de imperativo egin = 'hacer'.

\subsubsection{La EMV bicasual o díptota intransitiva (ND)}

La estructura bicasual o díptota intransitiva (ND) se formó añadiendo a la estructura unicasual el indicador de dativo - $k i$ - y los sufijos de dativo, en este orden, y es muy regular en los verbos no auxiliares.

\begin{tabular}{|l|l|l|l|l|}
\hline & \multicolumn{2}{|c|}{ j-oa-n = 'ir' } & \multicolumn{2}{c|}{ e-go-n = 'estar' } \\
\hline $\mathrm{N}_{1}$ & n-oa- -ki-o & yo le voy & n-a-go- -ki-o & yo le estoy \\
$\mathrm{N}_{2}$ & oa- -ki-o & tú le vas & a-go- -ki-o & tú le estás \\
$\mathrm{N}_{3}$ & d-oa- -ki-o & él/ella/ello le va & d-a-go- -ki-o & él/ella/ello le está \\
$\mathrm{N}_{4}$ & g-oa-z-ki-o & nosotros/as le vamos & g-a-go-z-ki-o & nosotros/as le estamos \\
$\mathrm{N}_{5}$, & z-oa-z-ki-o & vos le vais & z-a-go-z-ki-o & vos le estáis \\
$\mathrm{N}_{5}$ " & z-oa-z-ki-o-te & vosotros/as le vais & z-a-go-z-ki-o-te & vosotros/as le estáis \\
$\mathrm{N}_{6}$ & d-oa-z-ki-o & ellos/ellas le van & d-a-go-z-ki-o & ellos/ellas le están \\
\hline
\end{tabular}

Tabla 12. El sufijo de plural -z y el sufijo de plural -de en posición final en los SMV(ND).

En el verbo auxiliar, en cambio, la estructura es muy irregular a causa de las modificaciones que ha sufrido a lo largo de la historia reciente de la lengua vasca. Se confirma que el verbo auxiliar bivalente intransitivo original es izan (ser), aunque actualmente sólo se conserva en algunos dialectos periféricos como el vizcaíno u occidental y la parte occidental del guipuzcoano. Las flexiones de $1^{\mathrm{a}}$ y $2^{\mathrm{a}}$ persona plural de nominativo fueron sustituidas por las mismas del subjuntivo de la estructura bicasual transitiva, que también utilizan el verbo auxiliar izan pero con el sufijo de plural -it-. Dicho sufijo de plural -it- seguido de la raíz = iza- originó la actual raíz $=-i t z a->-t z a-$, que más tarde se extendió también a las flexiones de $1^{\mathrm{a}}$ y $2^{\mathrm{a}}$ persona singular. No lo llegó a hacer, sin embargo, en algún dialecto como el alto-navarro septentrional, que ha conservado la antigua raíz -iza- en la $1^{\mathrm{a}}$ persona singular. 


\begin{tabular}{|l|l|l|l|l|l|}
\hline & $\mathrm{NE}$ & & $\mathrm{ND}$ & \\
\hline $\mathrm{N}_{1} \mathrm{E}_{3}$ & n-a- -za- -la & que (él) me haya & $\mathrm{N}_{1} \mathrm{D}_{3}$ & n-a- -iza-i-o & yo le soy \\
$\mathrm{N}_{2} \mathrm{E}_{3}$ & a- -za- -la & que (él) te haya & $\mathrm{N}_{2} \mathrm{D}_{3}$ & a- t-za-i-o & tú le eres \\
$\mathrm{N}_{3} \mathrm{E}_{3}$ & d-e- -za- -la & que (él) le haya & $\mathrm{N}_{3} \mathrm{D}_{3}$ & z-a- -i-o & él le es \\
$\mathrm{N}_{4} \mathrm{E}_{3}$ & g-a-it-za- -la & que (él) nos haya & $\mathrm{N}_{4} \mathrm{D}_{3}$ & g-a-it-za-i-o & nosotros le somos \\
$\mathrm{N}_{5} \mathrm{E}_{3}$ & z-a-it-za- -la & que (él) os haya (a vos) & $\mathrm{N}_{5} \mathrm{D}_{3}$ & z-a-it-za-i-o & vos le sois \\
$\mathrm{N}_{5} \mathrm{E}_{3}$ & z-a-it-za-te-la & que (él) os haya (a vosotros) & $\mathrm{N}_{5 "} \mathrm{D}_{3}$ & z-a-it-za-i-o & vosotros le sois \\
$\mathrm{N}_{6} \mathrm{E}_{3}$ & d- -it-za- -la & que (él) le haya (a ellos) & $\mathrm{N}_{6} \mathrm{D}_{3}$ & z-a- -i-o & ellos le son \\
\hline
\end{tabular}

Tabla 13. $\mathrm{SMV}\left(\mathrm{NE}_{3}\right)$ del pres. de subjuntivo de izan y $\mathrm{SMV}\left(\mathrm{ND}_{3}\right)$ del pres. de indicativo de ekin/izan.

En las flexiones de $3^{\text {a }}$ persona de nominativo de todos los dialectos, excepto en algunas localidades como Echarri-Aranaz y Huarte-Araquil, se añadió el indicador de alocutivo -ientre el prefijo personal $d$ - y el infijo $-a$ - de presente para diferenciarse de las mismas flexiones del verbo ekin (inculcar, insistir). En el grupo inicial [d-i-a-] se produjo una evolución fonética $\left(d-i_{-}>y_{-}>d d->d x_{-}>x_{-}>j_{-} / z_{-}\right)^{24}$, en parte paralela a la castellana, que ya fue descrita por Schuchardt (1893) y cuyas fases se han conservado en vizcaíno u occidental, originándose en último término el prefijo $j$ - o el prefijo $z$-, este último por despalatalización del prefijo $x$-. Modernamente, en todos los dialectos salvo los occidentales (vizcaíno u occidental y parte occidental del guipuzcoano), las flexiones de $3^{\mathrm{a}}$ persona de nominativo se sustituyeron por las de $3^{\text {a }}$ persona de nominativo y ergativo de la estructura tricasual de los verbos auxiliares trivalentes utilizados en cada dialecto (el verbo ukan/iraun en bajo-navarro, suletino y roncalés, y el verbo edin en alto-navarro, labortano y parte oriental del guipuzcoano), sustituyendo a su vez el prefijo $d$ - por el z-. Por último, el verbo edin = 'coger' acabó sustituyendo al izan = 'ser' original también en las flexiones de $1^{\mathrm{a}}$ y $2^{\mathrm{a}}$ persona de los dialectos centrales como el alto-navarro meridional (ANM) ${ }^{25}$.

La evolución fonética del grupo [d-i-a-] ha sido la misma en las estructuras alocutivas, que se han formado al añadirle a las no alocutivas los sufijos de $2^{\mathrm{a}}$ persona singular masculino y femenino, $-k$ y $-n$, tal como se ha conservado en los dialectos orientales (roncalés, suletino y parte del bajo-navarro). De esas estructuras alocutivas procede el infijo $-i-$. En los verbos auxiliares, en cambio, se utilizaron las dos flexiones de $2^{\text {a }}$ persona singular de la estructura inmediatamente más compleja y, más tarde, se les añadió el indicador de alocutivo $-i$ - entre el prefijo de $3^{\mathrm{a}}$ persona $d$ - y el infijo de presente $-a$-, se produjo una evolución fonética del grupo [d-i-a-] $\left(d-i_{-}>y_{-}>d d->d x_{-}>x_{-}>j-/ z_{-}\right)$, en

\footnotetext{
${ }^{24}$ Por ejemplo, yat, dxat, xat, jat, zat, zait, zaida, zaira, etc. proceden todas ellas de *diakida, analizado $* d-\mathbf{i}-a-k i-$ $d a$, donde el infijo - $i$ - es un indicador de dativo, que es el que diferencia esta forma verbal nor-nori de la nor-nork de ese mismo verbo. La $/ \mathrm{k} / \mathrm{se}$ ha conservado en la 3 persona (yako, dxako, xako, jako, zako, zayo, zio, zau... < d-ia-ki-o). Por lo tanto, el infijo -i- se añadió a dakit, dakio, etc. formando diakit, diakio, etc. y la [dj-] inicial evolucionó fonéticamente de diversas formas, igual que en las flexiones alocutivas, según ya describió ya Schuchardt (cit. Yrizar 1981: 307 ss.) y confirma Michelena (1961: 173-174). En Etxarri-Aranaz, Lizarraga y Unanua (guipuzcoano de Navarra), así como en Huarte-Arakil e Irañeta (alto-navarro septentrional), se conserva la [d] original (dakiyo, dakit, respectivamente).

${ }^{25}$ Igual que ocurre en la estructura bicasual intransitiva, los mapas dialectológicos reflejan este proceso según las normas areales de la Geografía Lingüística (Bartoli, 1925, 1945; Coseriu, 1977), presentando las fases más antiguas en los dialectos periféricos (vizcaíno) y las más modernas en los dialectos centrales (alto-navarro meridional).
} 
parte paralela a la castellana y que ya fue descrita por Schuchardt (1893), y se originó finalmente el prefijo $z$ - por despalatalización del prefijo $x$-. Desde el punto de vista diacrónico, las innovaciones lingüísticas se produjeron con menor intensidad en las estructuras alocutivas que en sus estructuras no alocutivas correspondientes y, por tanto, en las alocutivas se han conservado mejor las fases antiguas de su proceso de formación.

\subsubsection{La EMV tricasual o tríptota (NDE)}

La estructura tricasual o tríptota (NDE) se formó añadiendo todos los sufijos de dativo a la estructura bicasual transitiva e intercambiando después las funciones casuales de los sufijos personales como consecuencia de la inexistencia de sufijo de $3^{a}$ persona de ergativo, de manera que la estructura NED formada inicialmente se transformó en la actual estructura NDE, aunque la antigua NED se ha conservado en algunas flexiones de algunos dialectos.

$$
\begin{gathered}
\mathrm{NE}+\mathrm{D}=\mathrm{NED} \\
\mathrm{NED}>\mathrm{NDE}
\end{gathered}
$$

Uno de los problemas más difíciles de la estructura tricasual ha sido la identificación de la raíz del verbo auxiliar trivalente que presenta una vocal /i/ como único elemento morfológico además de los personales, ya que su pertenencia a un supuesto verbo *io, como acepta la Euskaltzaindia, a un verbo *ion o *iron, como ha sugerido Trask (1990), su origen en el sufijo indicador de dativo -ki-, como defendieron Schuchardt (1893), Lafon (1943) y Rebuschi (1984), o su identificación con el indicador de alocutivo -i-, como indicó Azkue (MD), no la explicaban de forma satisfactoria, ni en el plano fonético ni en el morfológico. Tras comprobar todas las explicaciones que se han ofrecido y obtener de ellas un resultado negativo, por el método de demostración indirecta hemos llegado a la conclusión de que la estructura con raíz - $i$ - del verbo auxiliar trivalente corresponde al verbo edin = 'coger', con desaparición de la /d/ intervocálica y reducción del diptongo [ai] (por ejemplo, $* d-a-d i-t>$ $d-a-i-t>d-i-t=$ '(él/ella/ello) me lo/la ha'). La antigua raíz -di- aparece, en efecto, en algunas variantes dialectales alto-navarras de pasado ${ }^{26}$. Sin embargo, la estructura homónima con raíz - $i$ - del verbo que significa 'hablar, decir' corresponde al antiguo verbo *enausi = 'hablar, decir', cuya evolución fonética ha sido tan profunda que lo ha igualado al verbo edin = 'coger'. Sus numerosas variantes dialectales, permiten la reconstrucción del primitivo verbo *enausi (hablar, decir), a partir del cual se formó el gentilicio euskera (escrito enusquera por Garibai) como indicó Irigoien $(1977,1988)^{27}$. El verbo auxiliar trivelente vizcaíno u occidental es eutsi (asir, aguantar, sostener), como defendió Trask

\footnotetext{
${ }^{26}$ Por ejemplo, $g$-i-n-di-o = 'nosotros/as se lo/la hemos a él/ella/ello', $g$-i-n-di-zki-zu = 'nosotros/as os lo/la hemos a vos', $g$-i-n-di-zki- $a=$ 'nosotros/as te (masc.) lo/la hemos', $z$-i-n-di-ra-te = 'vosotros/as me lo/la habéis'.

${ }^{27}$ En efecto, se trata de dos verbos distintos, ya que *ion con significado de 'hablar, decir' procede de *inon y éste, por evolución fonética, del antiguo *enausi / *enautsi, que ha originado las variantes enusi, eusi, ehüsi, ihausi e $i$ usi. El verbo *irautsi, en cambio, es el causativo del *enausi / *enautsi y su forma antigua fue *eranausi / *eranautsi, de la que proceden por evolución fonética las variantes erauntsi, erhausi, herausi, erausi, erasi, erauntsi, erautxi y eratsi.
} 
(1995), pero no procede de edun+tsi, ni tampoco tiene un origen común con los verbos auxiliares trivelentes de los demás dialectos, como defendieron Schuchardt (1893), Lafon (1943) y Rebuschi (1984), porque entonces no se cumplirían las leyes fonéticas vascas. El sufijo es -ts-, procede de $e$-uts-i por falso análisis y se extendió a partir de dicho verbo a otros verbos auxiliares vizcaínos u occidentales como egin = 'hacer ${ }^{28}$.

Parece deducirse que el verbo auxiliar trivalente fue originalmente ukan (por ejemplo, $d-a-u-t / d-a-d a=$ '(él/ella/ello) me lo/la ha') cuya flexión $\mathrm{ND}_{3} \mathrm{E}$, en vez de emplear el sufijo - o como los demás verbos trivalentes, fue sustituida por la del verbo iraun (durar) para indicar la $3^{\mathrm{a}}$ persona singular de dativo (por ejemplo, $d$ - $a$-rau $>d-a-r o>d-a-o>d-a-k-o=$ '(él/ella/ello) se lo/la ha a él/ella/ello') y evitar la confusión con la flexión $\mathrm{N}_{3} \mathrm{E}$, originándose así un Sistema Morfológico mixto formado por dos verbos, ukan e iraun. En los textos literarios, sin embargo, se utilizó el verbo auxiliar iraun en todas las flexiones, según se utilizaba entonces en labortano y en guipuzcoano septentrional. En los últimos siglos, cayeron en desuso las flexiones de $1^{\mathrm{a}}$ y $2^{\mathrm{a}}$ persona de nominativo, que se documentan en las obras de Leiçarraga (1571) principalmente, y a partir de entonces se emplearon únicamente las de $3^{\mathrm{a}}$ persona de nominativo, por lo que el único prefijo personal que se utiliza actualmente en presente es $d$ - y, en pasado, se utiliza exclusivamente la estructura EDN propia de las flexiones de $3^{\text {a }}$ persona de nominativo. Este SMV original sólo se ha conservado en todas las flexiones y en todas las personas en bajo-navarro y roncalés, que son dos dialectos periféricos, mientras que en labortano ha sido sustituido en las flexiones de $3^{\text {a }}$ persona singular y plural de dativo por el SMV más moderno del alto-navarro. En vizcaíno u occidental, sólo se ha conservado en la $2^{\mathrm{a}}$ persona singular de dativo $\mathrm{y}$, en los demás dialectos, se ha conservado sólo en algunas personas aisladas.

\footnotetext{
${ }^{28}$ Por ejemplo, $d-a-g i-o-g u-n>d-a-i-o-g u-n>d-e-i-o-g u-n=$ 'para que nosotros/as se lo hagamos a él/ella/ello' o $d-a-i-g u-z u-n=$ 'para que vos nos lo/la hagáis' carecen del infijo -ts-, pero $d-a-i-s k u-z u-n<* d-a-g i-t s-g u-z u-n=$ 'para que vos nos lo/la hagáis' ya lo ha añadido.
} 


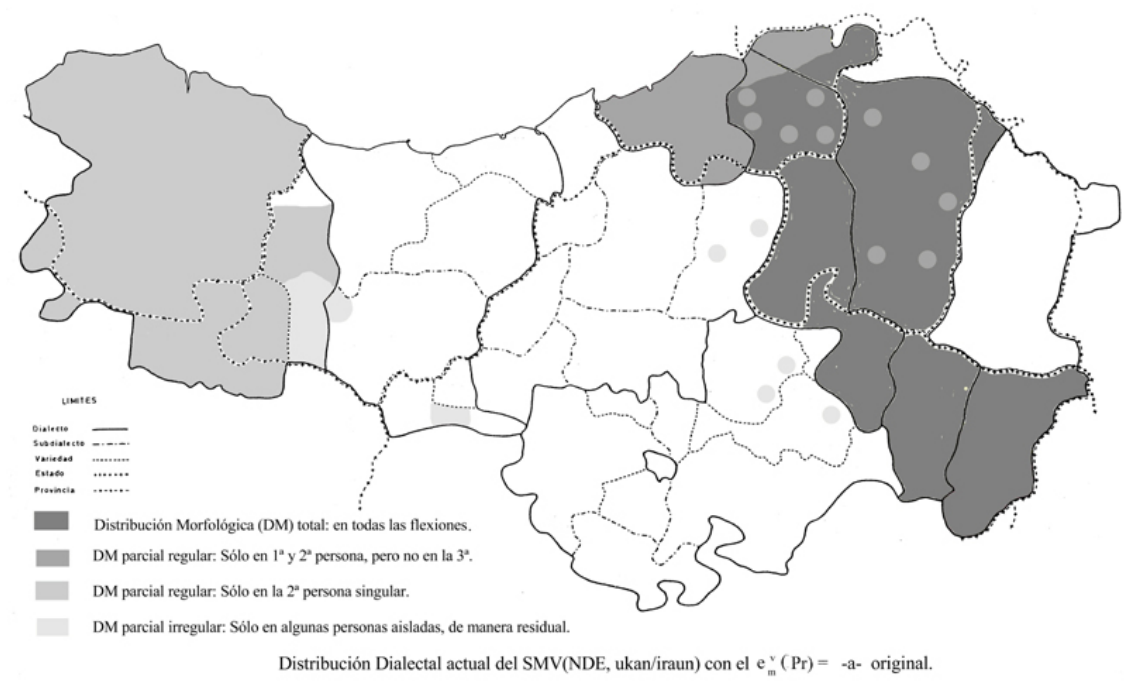

Mapa 2. Distribución dialectal (DD) del verbo auxiliar trivalente ukan/iraun con infijo - $a$-.

Además de esto, se produjo la evolución fonética de la estructura tricasual de $u k a n / i r a u n$, sobre todo del diptongo [au] del verbo ukan, que en los dialectos centrales (altonavarro, guipuzcoano o central y suletino) se redujo a /e/ o a $/ \mathrm{u} /$ (por ejemplo, $d-\boldsymbol{u}-t=$ '(él/ella/ello) me lo/la ha', $d-\boldsymbol{e}-g u=$ = (él/ella/ello) nos lo/la ha'), como ya explicó Michelena (1961). En el verbo iraun, propio de las flexiones de $3^{\mathrm{a}}$ persona de dativo, el infijo - $a-$ evolucionó a -e-por disimilación (por ejemplo, $d-\boldsymbol{e}-\mathrm{rau}>d-\boldsymbol{e}$-ro $=$ '(él/ella/ello) se lo/la ha a él/ella/ello') también en parte del alto-navarro septentrional, guipuzcoano o central y suletino, originándose este cambio fonético en guipuzcoano o en alto-navarro $\mathrm{y}$ extendiéndose al suletino por las vías de comunicación (Roncesvalles). 


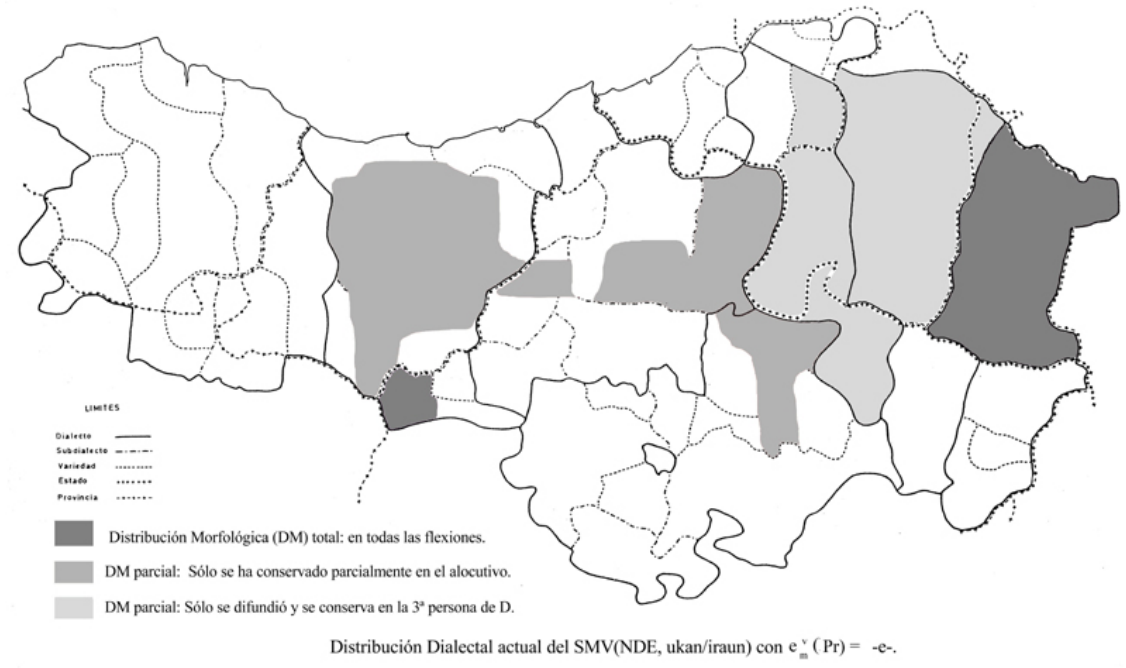

Mapa 3. Distribución dialectal (DD) del verbo auxiliar trivalente ukan/iraun con infijo -e-.

Después, este infijo - $a$ - evolucionó a -o- en la parte occidental del alto-navarro meridional y guipuzcoano meridional y de Etxarri-Aranaz por asimilación con la /o/ de la sílaba siguiente (por ejemplo, $d$-a-ro $>d$-o-ro $>d$-o-o $=$ '(él/ella/ello) se lo/la ha a él/ella/ello').

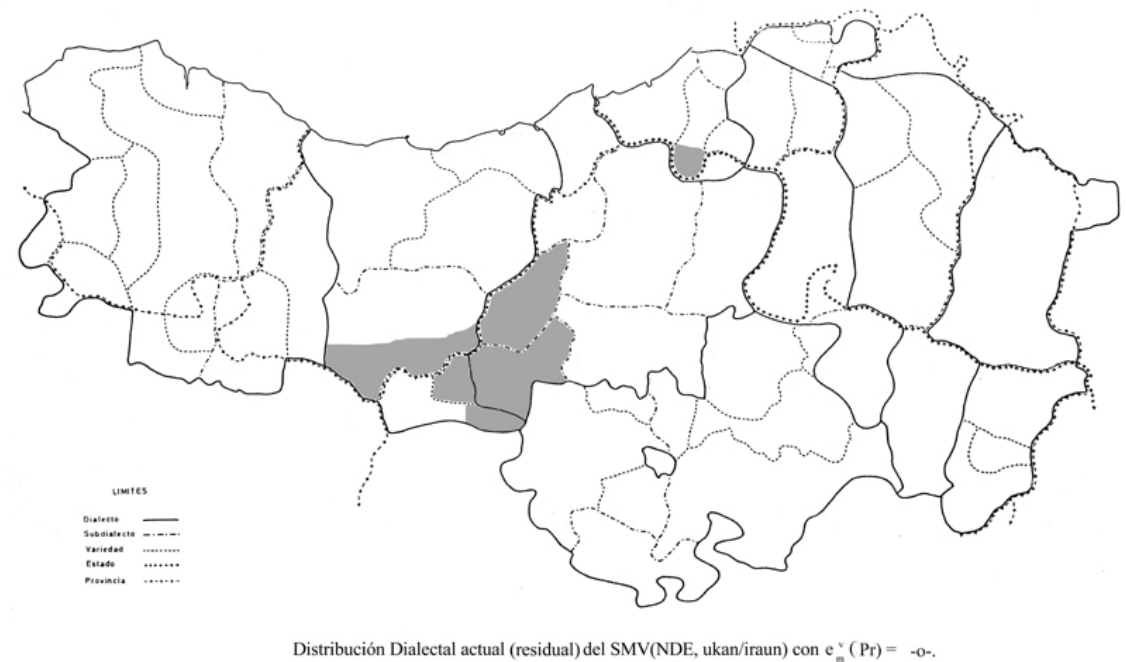

Mapa 4. Distribución dialectal (DD) del verbo auxiliar trivalente ukan/iraun con infijo -o-. 
En los dialectos septentrionales (labortano, bajo-navarro, suletino y roncalés), por el contrario, por analogía con la estructura bicasual intransitiva, se añadió modernamente el indicador de dativo -ki- en todas las flexiones en labortano y sólo en algunas flexiones en bajo-navarro, suletino y roncalés (por ejemplo, $d-a-r o>d-a-o>d-a-k-o=$ '(él/ella/ello) se lo/la ha a él/ella/ello', $d-a-u-g u>d-a-u-k i-g u>d-a-u-k i-u>d-a-u-k-u=$ '(él/ella/ello) nos lo/la ha'). Esta innovación se inició claramente en labortano, y luego se extendió a los demás dialectos orientales, primero al bajo-navarro y más tarde al suletino y al roncalés. También se extendió a algunas hablas vecinas del alto-navarro, pero de una manera superficial, sólo en algunas personas aisladas.

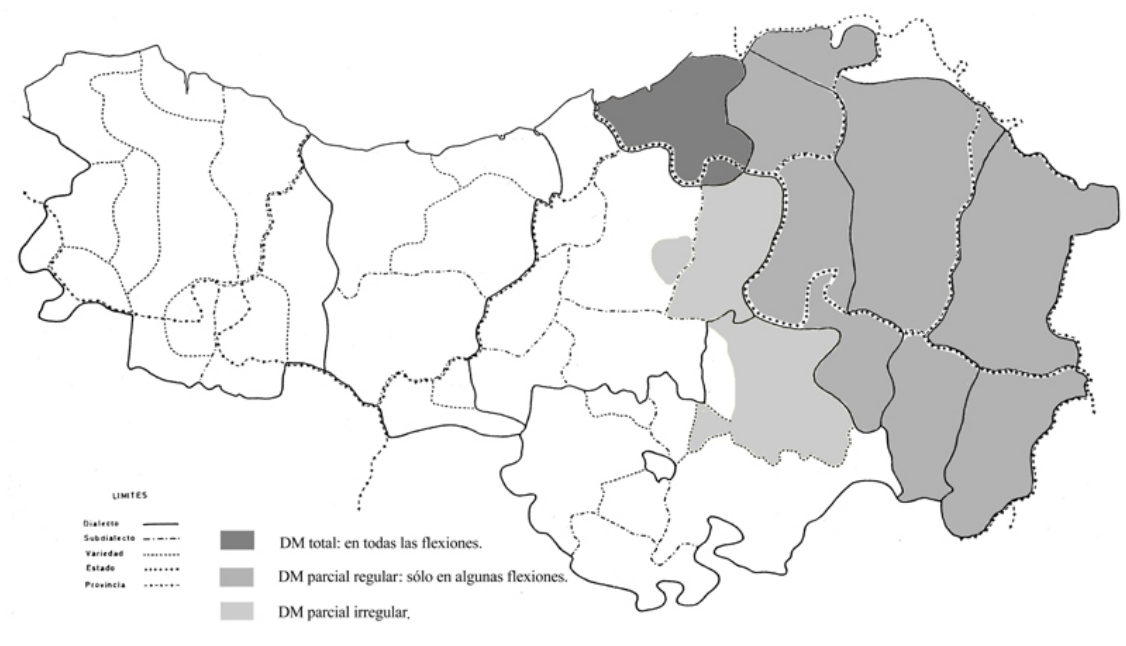

Distribución dialectal del SMV(NDE) con el Indicador de Dativo $\mathrm{e}_{\mathrm{m}}^{\vee}\left(\Delta_{\bullet}\right)=-$ ki- según la Distribución Morfológica (DM) de este último

Mapa 5. Distribución dialectal (DD) del verbo auxiliar trivalente $u k a n / i r a u n$ con sufijo -ki-.

No obstante, los cambios más significativos que se han producido en esta estructura tricasual de ukan/iraun consisten en la sustitución de estos dos verbos auxiliares originales por otros distintos. Así, en vizcaíno u occidental se sustituyeron por el verbo eutsi = 'asir, aguantar, sostener', que no es el ukan con sufijo -tsi como dijo Schuchardt (1893) y aceptaron Azkue (1923-1925), Lafon (1943), etc. (por ejemplo, $d$ - $a$-us- $t<* d-a-u t s-t=$ '(él/ella/ello) me lo/la ha', $d-a-u t s-o>d-a-u-t s-o=$ ('él/ella/ello) se lo/la ha a él/ella/ello'). 


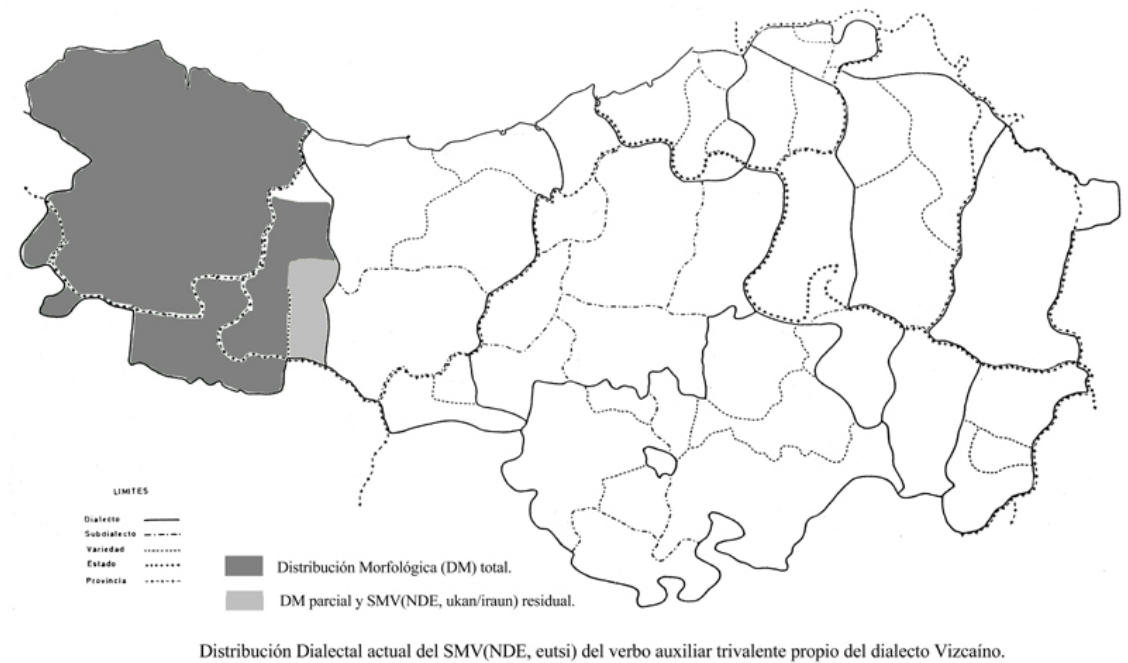

Mapa 6. Distribución dialectal (DD) del verbo auxiliar trivalente eutsi.

En el noreste del guipuzcoano y en parte del labortano, el verbo ukan se sustituyó por el verbo iraun en todas las flexiones, y ésta fue la estructura tricasual de iraun utilizada en los textos literarios y se ha conservado en esa área habiendo evolucionado fonéticamente mediante la desaparición de la / $\mathrm{r}$ / intervocálica y la posterior reducción a /o/ del diptongo [au] de la raíz (por ejemplo, $d$-i-rau-te $>d$-i-au-te $>d$-i-o-te $=$ 'yo se lo/la he a ellos/ellas'). El sufijo -z-ki más el sufijo -o de $3^{\text {a }}$ persona singular de dativo (-z-ki-o) evolucionó fonéticamente al sufijo -z-ka y, después, a los sufijos -tza, -tze y -tzi en algunos dialectos (guipuzcoano o central y suletino) (por ejemplo, $d-i-r a u-z k i-o-t>d-i-o-z k-a-t>d-i-o-t z a-t$ $=$ 'yo se lo/la he a él/ella/ello'). 


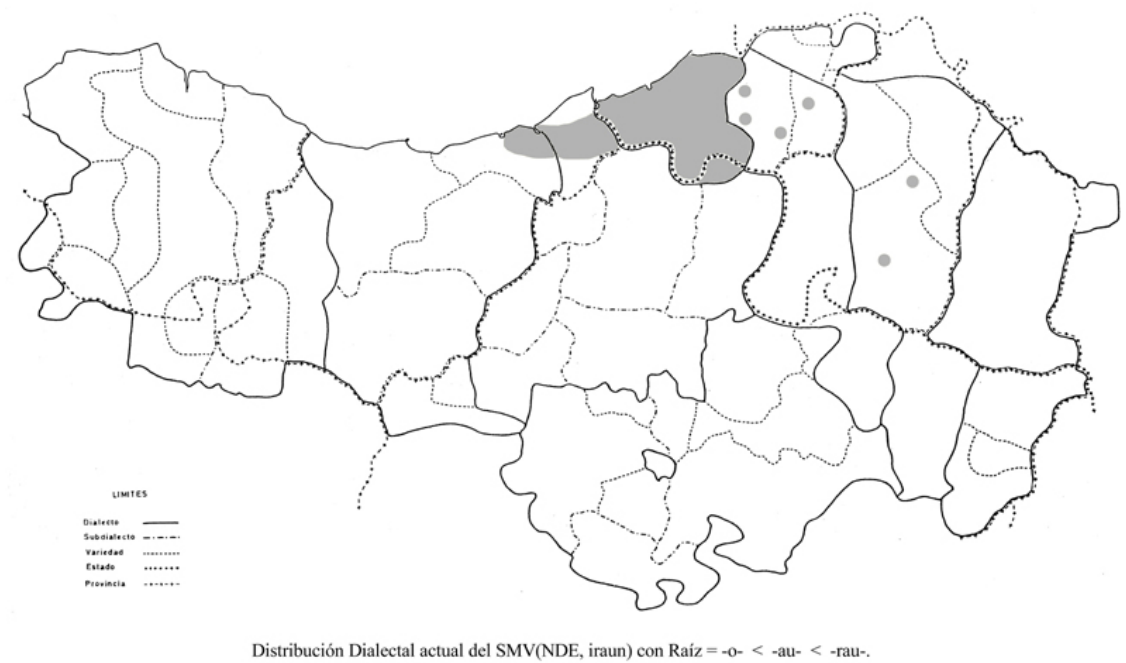

Mapa 7. Distribución dialectal (DD) del verbo auxiliar trivalente iraun.

Finalmente, los verbos auxiliares ukan/iraun se sustituyeron en alto-navarro por el verbo edin $=$ 'coger', reduciendo a $/ \mathrm{i} /$ el diptongo [ai] (por ejemplo, $d-\mathbf{i}-t<d-a-\mathbf{i}-t<d-a-d i-t$ $=$ '(él/ella/ello) me lo/la ha', $d-i-o<d-a-i-o<d-a-d i-o=$ '(él/ella/ello) se lo/la ha a él/ella/ello'). Esta innovación se inició claramente en alto-navarro meridional y el nuevo verbo auxiliar edin se extendió más tarde al alto-navarro septentrional y al guipuzcoano o central, aunque en este último dialecto sólo se utilizó en la estructura tricasual no alocutiva,mientras que la alocutiva siguió conservando el antiguo verbo auxiliar ukan/iraun. Ya en el siglo XVIII, se extendió al labortano, aunque sólo en las flexiones de $3^{\text {a }}$ persona de dativo, y lo mismo ocurrió en algunas localidades aisladas, pero bien comunicadas, del bajo-navarro, del suletino y del roncalés. La expansión del nuevo verbo auxiliar edin se produjo, por tanto, hacia el norte siguiendo las vías de comunicación. 


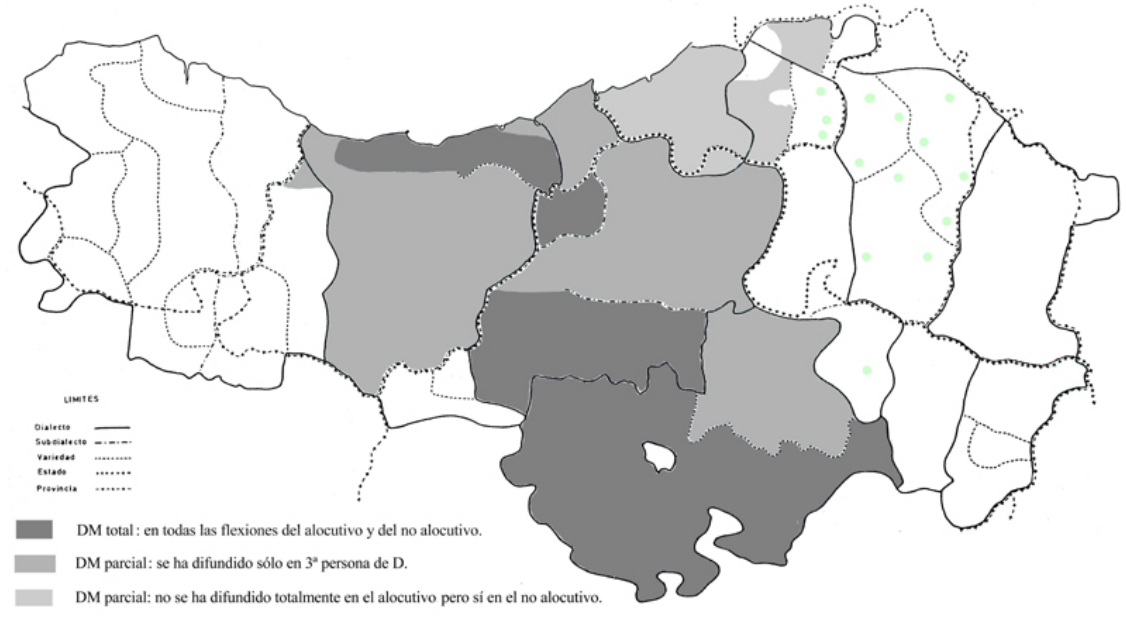

Distribución Dialectal de los SMV(NDE, edin) según la Distribución Morfológica (DM) que presentan.

Mapa 8. Distribución dialectal (DD) del verbo auxiliar trivalente edin.

Sin embargo, en algunas localidades periféricas se ha conservado el antiguo diptongo [ai] del verbo edin (por ejemplo, $d-a-i-e<* d-a-d i-e=$ '(él/ella/ello) se lo/la ha a ellos/ellas', $d-a-i-k-o<* d-a-i-o<* d-a-d i-o=$ '(él/ella/ello) se lo/la ha a él/ella/ello').

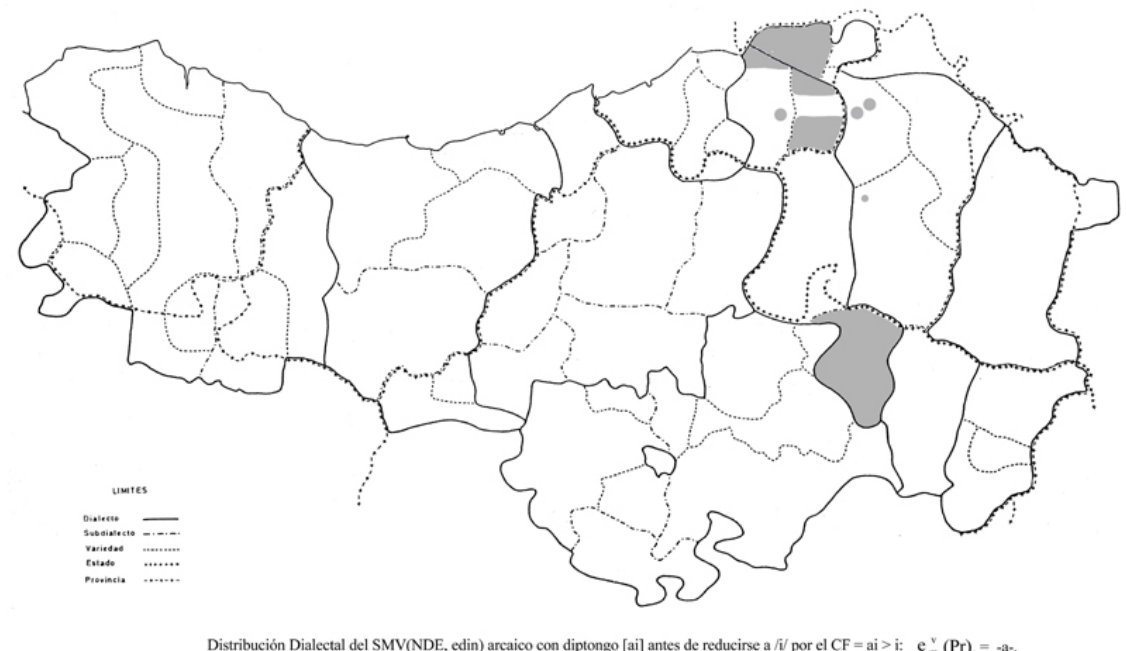

Mapa 9. Distribución dialectal (DD) del verbo auxiliar trivalente edin con diptongo [ai]. 
El antiguo sufijo de plural $-z$ sólo se ha conservado en vizcaíno u occidental (por ejemplo, $d-a-u t s-a-z=$ '(él/ella/ello) se los/las ha a él/ella/ello'), mientras que en todos los demás dialectos se utilizó su compuesto -zki- (por ejemplo, $d$-i-zki-o $=$ '(él/ella/ello) se los/las ha a él/ella/ello' es el plural de $d-i-o=$ '(él/ella/ello) se lo/la ha a él/ella/ello'). En la mayor parte del alto-navarro, este último sufijo se ha sustituido a su vez por el infijo -it-, que en una parte del alto-navarro septentrional (ANS) ha evolucionado al -i $\bar{t}$-, palatalizando la $/ \mathrm{t} /$ detrás de $/ \mathrm{i} /$ (por ejemplo, $d$-it-i-o $>* d-\mathbf{i} \bar{t}-i-o>\bar{t}-i-O=$ '(él/ella/ello) se los/las ha a él/ella/ello’).

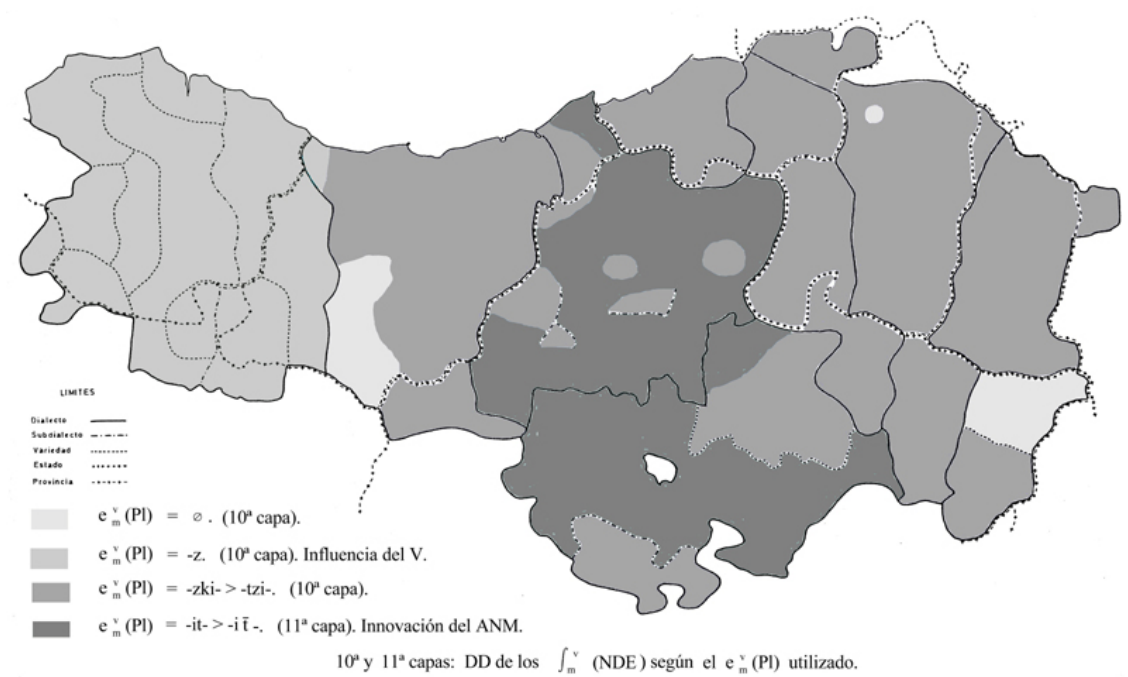

Mapa 10. Distribución dialectal de los elementos morfológicos de plural en la estructura tricasual.

\section{Conclusiones}

Tras este estudio de la estructura morfológica verbal vasca mediante el método comparativo de reconstrucción interna, se ha podido describir cómo era dicha estructura en el período anterior a la romanización y su evolución en sucesivas fases cronológicas que afectaron en mayor o menor medida a las distintas áreas del territorio de habla vasca, de modo que se pueden establecer auténticos estratos geolingüísticos que corroboran los principios de la Geografía Lingüística enunciados por Mateo Bartoli (1925, 1945; Coseriu, 1977). El área central de la que han surgido casi todas las innovaciones lingüísticas después de la romanización ha sido la del dialecto alto-navarro meridional (ANM), concretamente la ciudad de Pamplona (capital del antiguo reino de Navarra) y su área circundante. Una segunda área central ha sido la del dialecto occidental o vizcaíno. 


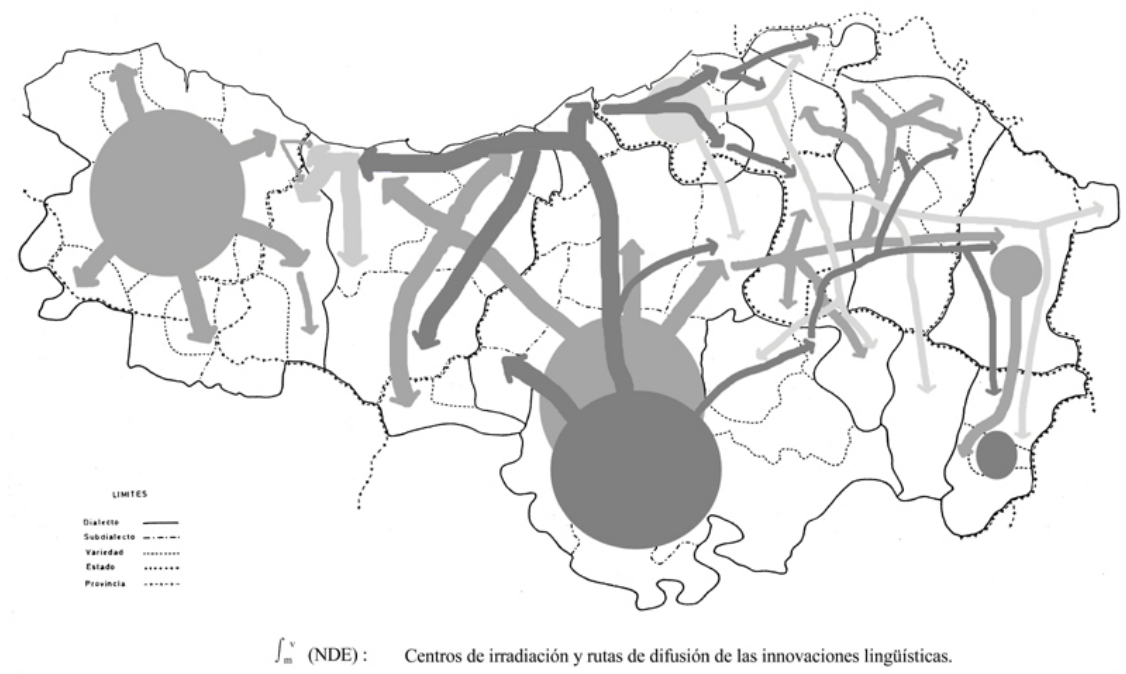

Mapa 11. Centros de irradiación y rutas de difusión de las innovaciones lingüísticas.

Un ejemplo de esta estratificación geolingüística es la del sufijo de plural -de / -e / -te y sus variantes dialectales que, desglosado en las distintas estructuras morfológicas, constituye un ejemplo muy ilustrativo de la expansión de los sufijos de plural innovadores a partir del dialecto alto-navarro meridional. Así, en la estructura tricasual, el sufijo de $3^{\text {a }}$ persona de plural -te (el más moderno) sólo existe en parte del alto-navarro y en labortano ( $d$-i-o-te $=$ 'ellos/ellas se lo/la han a él/ella/ello', en vez de $d-i-e$, por ejemplo), en la estructura bicasual intransitiva (z-a-i-o-te = 'ellos/ellas le han a él/ella/ello', por ejemplo) ha hecho desaparecer las variantes más antiguas en esos dialectos (sin distinción de plural como en $d-i-o=$ 'ellos/ellas se lo/la han a él/ella/ello', por ejemplo), en la estructura bicasual transitiva se ha extendido al bajo-navarro ( $d$-u-te = 'ellos/ellas lo/la han', en vez de $d-u$-e, por ejemplo) y en la estructura unicasual lo ha hecho también al guipuzcoano o central en la $2^{\mathrm{a}}$ persona de plural (z-e-ra-te = 'vos sois', por ejemplo). El sufijo -de (el más antiguo), en cambio, se ha conservado en los dialectos periféricos más extremos, en vizcaíno u occidental en la estructura bicasual transitiva y $(d-a-u-r i-e<d-a-u-d i-e<* d-a-$ $u-d e-e=$ 'ellos/ellas lo/la han', por ejemplo) en suletino en la estructura unicasual (z-i-ra-de $=$ 'vos sois', por ejemplo).

El sistema morfológico verbal original reconstruido por medio de esta metodología muestra una gran regularidad formal y estructural interna, además de una gran uniformidad en relación al territorio, lo que nos da la certeza de una lengua vasca común y uniformemente hablada en todo el territorio vasco antes de la romanización, que contradice la hipótesis de Uhlenbeck (1947). La singularidad del dialecto vizcaíno u occidental con respecto a los demás dialectos vascos es posterior a la romanización y permite hablar de dos grandes grupos dialectales: el occidental, que está formado por el vizcaíno (o dialecto 
occidental propiamente dicho), y el centro-oriental, que presenta un continuum lingüístico entre todos los demás dialectos.

La estructura morfológica verbal prerromana debió de ser muy estable durante un período más o menos largo pero no fue la más antigua, permitiendo reconstruir, o al menos atisbar, cómo era la estructura morfológica verbal anterior e, incluso, la más antigua a la que se puede llegar mediante el método comparativo de reconstrucción interna. Como consecuencia de ello, más que de "protovasco", ya se puede hablar de un vasco posterior a la romanización, con unas características bien conocidas; de un vasco anterior a la romanización, que presenta unas características diferentes, pero igualmente bien conocidas, y sería el vasco del primer milenio antes de Cristo $^{29}$; y se puede hablar también de un vasco arcaico, anterior por lo menos al primer milenio y a las influencias indoeuropeas, y cuyas características también son reconocibles.

Se pueden observar, por otra parte, dos orientaciones en la investigación diferentes en lo que respecta al verbo vasco, una más empírica y descriptiva representada sobre todo por L. L. Bonaparte (1863, 1869), R. M. de Azkue (1905-1906, 1923-1926) y L. Michelena (1957, 1961, 1964, 1974); y otra más teórica y de alcance más general, representada por H. Schuchardt (1893, 1923), R. Lafon (1943), R. L. Trask (1977, 1990, 1997) y Rebuschi (1984, 1997), principalmente. Se confirman, pues, la mayoría de las conclusiones de la primera de estas dos líneas de investigación y lo expuesto anteriormente se sitúa en esta primera orientación en cuanto a la importancia de los datos. No obstante, en la exposición anterior también se contribuye a la segunda orientación. Sin embargo, la metodología matemática permite llegar más lejos en la investigación, explicando fenómenos o proporcionando explicaciones nuevas que tienen mayor alcance descriptivo y explicativo, que son coherentes y no se contradicen entre sí. Tal es así que, utilizando el método de reconstrucción interna, ha sido posible describir el proceso de formación de la estructura morfológica verbal de la lengua vasca.

\section{Referencias bibliográficas}

Alberdi, J. (1995): "The Development of the Basque System of Terms of Address and the Allocutive Conjugation". En Hualde, J. I.; Lakarra, J. A. y Trask, R. L. (eds.), Towards a History of the Basque Language, Serie "Current issues in linguistic theory", vol. 131, Amsterdam / Filadelfia, John Benjamins Publishing Company, págs. 275-293.

Axular, P. de (1643): Gero, Bordeaux, G. Milanges, ed. facsímil en Revista Internacional de Estudios Vascos, IV a XXIV, hasta cap. XLVII, París - San Sebastián; ed. con introducción y traducción de L. Villasante, Barcelona, 1964; Repr. L. Villasante, Oñati, Jakin, Arantzazu, 1976; Repr., Bilbao, Euskaltzaindia, 1988.

Azkarate, M. y Altuna, P. (2001): Euskal morfologiaren historia, Donostia, Elkarlanean.

Azkue, R. M. de (1905-1906): Diccionario vasco-español-francés, I-II, Bilbao / Tours, A. Mame, Repr., Bilbao, La Gran Enciclopedia vasca, 2a ed., 1969, Repr. Bilbao, Euskaltzaindia, 1984.

${ }^{29}$ El vasco anterior a la romanización era también la lengua de Aquitania y sus límites se extendían, pues, desde el Nervión hasta el Garona (Gorrochategui, 1984; 1985a; 1985b). 
Azkue, R. M. de (1905-1906): "Morfología Vasca", Euskera IV-VI, Bilbao. Repr. en Morfología Vasca (gramática básica dialectal del euskera), Bilbao, La Gran Enciclopedia Vasca, tomos I y II, $2^{\text {a }}$ ed., 1969.

Azkue, R. M. de (1923-1925): "Primer apéndice de morfología vasca (conjugación del verbo guipuzcoano)”, Euskera XII (págs. 87-206), XIV (197-223), Bilbao. Repr. en Morfología Vasca (gramática básica dialectal del euskera), Bilbao, La Gran Enciclopedia Vasca , tomo III, $2^{\mathrm{a}}$ ed., 1969.

Bähr, G. (1926-1935): "Estudio sobre el verbo guipuzcoano", Revista Internacional de Estudios Vascos, París - San Sebastián.

Bakker, P. (1984): "The order of affixes in the Basque synthetic verb", Anuario del Seminario de Filología Vasca 'Julio de Urquijo' 18:2, págs. 63-87.

Bartoli, M. (1925): Introduzione alla neolinguistica. Principi, scopi, metodi, Ginebra-Florencia.

Bartoli, M., (1945): Saggi di linguistica spaziale, Turín, Vincenzo Bona.

Betolaza, J., [J. Betolaça] (1596): Doctrina christiana en romance y en basquence, Bilbao, Imp. Por Pedro C. de Ybarra. En Michelena, L. (ed.) en el Boletín de la Real Sociedad Vascongada de Amigos del País, XI, 1, 1955, págs. 92-100.

Bonaparte, L. L. (1863): La Carte des sept provinces Basques en montrant la délimitation actuelle de l'euskara et sa division en dialectes, sous-dialectes e variétés, Londres, Standford Geographical Establishment.

Bonaparte, L. L. (1869): Le verbe basque en tableaux, Londres, Strangeways \& Walden.

Bonfante, G. (1945): “On reconstruction and linguistic method”, Word 1, págs. 83-94 y 132-161. Citado por Michelena, L. (1957): "Las antiguas consonantes vascas". Repr. en J. I. Hualde, J. A. Lakarra y R. L. Trask (eds.), Towards a History of the Basque Language, en la Serie "Current issues in linguistic theory", vol. 131, Amsterdam / Filadelfia, John Benjamins Publishing Company, 1995, p. 101.

Brettschneider, G. (1979): "Typological characteristics of Basque". En Plank, F. (ed.), Ergativity. Towards a Theory of Grammatical Relations, London / New York / Toronto / Sydney / San Francisco, Academic Press.

Camino, I. (1997), Aezkoako euskararen azterketa dialectologikoa, Iruñea, Nafarroako Gobernua.

Camino, I. (ed.) (1998), Nafarroako hizkerak. Nafarroako Euskal Dialektologiako Jardunaldietako Agiriak. Iruñea, 1997ko azaroa (24-28), Bilbo, Udako Euskal Unibertsitatea.

Coseriu, E. (1977): El hombre y su lenguaje: estudios de teoría y metodología lingüística, Madrid, Gredos, 1985.

Dechepare, B. (1545): Linguae Vasconum Primitiae, Bordeaux; Rpr. H. Schuchardt (1923), Primitiae Linguae Vasconum. Einführung ins Baskische, Halle, M. Niemeyer, traducción española Salamanca, Universidad de Salamanca, Tesis y Estudios Salmantinos 3, 1947; ed. fac. imprenta López Mendizábal, Tolosa, 1933 , Linguae Vasconum Primitiae (edición facsímil en La Gran Enciclopedia Vasca, t. I, 73.127). Numeración de cantos y traducción de Lafon, R. Boletín de la Real Sociedad Vascongada de Amigos del País, VII, (1951), págs. 485-504, VIII, (1952), págs. 3-20., Rpr. P. Altuna, Linguae Vasconum Primitiae, Bilbao, Mensajero, 1987.

Domene Verdú, J. F. (2007a): Lingüística y matemáticas: El proceso de formación de la estructura morfológica verbal de la lengua vasca, Serie Tesis doctorales Servicio de Publicaciones. Euskal Herriko Unibertsitatea / Universidad del País Vasco.

Domene Verdú, J. F. (2007b): "El origen del afijo de plural -it-", Fontes Linguae Vasconum, 104, págs. 33-58.

Domene Verdú, J. F. (2007c): “Los afijos temporales vascos”, Fontes Linguae Vasconum, 105, págs. 189-217. 
Echaide, A. M. (1974): "Ordenación cartográfica del Erizkizundia", Anuario del Seminario de Filología Vasca 'Julio de Urquijo', págs. 113-174.

Echaide, A. M. (1984): Erizkizundi Irukoitza, Bilbao, Academia de la lengua vasca - Euskaltzaindia, Iker 3.

Euskaltzaindia (1925-1930): "Erizkizundi irukoitza (Herriz-Herri)”, Euskera VI-XI.

Euskaltzaindia, (1925-1930): "Erizkizundi irukoitzari Bizkaiak erantzun diona", Euskera VI (IV), (1925), págs. 16-36; VII (I), (1926), págs. 38-56; VII (II), (1926), págs. 45-59; XI, (1930), págs. $62-71$.

Euskaltzaindia (1981): Euskalarien nazioarteko jardunaldiak, Bilbo, Euskaltzaindia, Iker 1.

Euskaltzaindia (1987): Euskal gramatika: lehen urratsak II, Bilbao, Euskaltzaindia.

Gaminde, I. (1984): Aditza Bizkaieraz, 3 tomos, Iruñea, Udako Euskal Unibertsitatea.

Gaminde, I. (1985): Aditza. Ipar eta Goi Nafarrera, 3 tomos, Iruñea, Udako Euskal Unibertsitatea.

Gladkij, A.V. y Melchuk, I.A. (1972): Introducción a la lingüística matemática, Barcelona, Ed. Planeta.

Gómez, R. y Sainz, K. (1995): "On the origin of the finite forms of the Basque Verb". En Hualde, J. I.; Lakarra, J. A. y Trask, R. L. (eds.), Towards a History of the Basque Language, Serie "Current issues in linguistic theory", vol. 131, Amsterdam / Filadelfia, John Benjamins Publishing Company, págs. 235-273.

Gorrochategui, J. (1984): Onomástica indígena de Aquitania, Bilbao, Universidad del País Vasco Euskal Herriko Unibertsitatea.

Gorrochategui, J. (1985a): "Lengua aquitana y lengua gala en la Aquitania etnográfica". En Symbolae L. Mitxelena oblatae, I, págs. 613-628.

Gorrochategui, J. (1985b): "Historia de las ideas acerca de los límites geográficos del vasco antiguo", Anuario del Saminario de Filología Vasca 'Julio de Urquijo', 19:2, págs. 571-594.

Gorrochategui, J. y Lakarra, J. A. (1996): "Nuevas aportaciones a la reconstrucción del Protovasco". En Francisco Villar \& José Encarnaçao (eds.), La Hispania prerromana (Actas del VI coloquio sobre Lenguas y Culturas prerromanas de la Península Ibérica, Coimbra, 13-15 de octubre de 1994), Salamanca, Universidad de Salamanca, págs. 101-145.

Harris, Z. S. (1971): Structures mathématiques du language, Paris, Ed. Dunod.

Heath, J. (1976): "Antipassivization: a functional typology", Proceedings of the Second Annual Meetting of the Berkeley Linguistic Society, págs. 202-211.

Heath, J. (1977): "Remarks on Basque verbal morphology". En Douglass Jr., W. A.; Etulain, R. y Jacobsen, W. H. (ed.), Anglo-american contributions to Basque studies. Essays in honor of Jon Bilbao, Reno, Univ. of Nevada, págs. 193-201.

Hualde, J. I.; Lakarra, J. A. y Trask, R. L. (eds.) (1995), Towards a History of the Basque Language, Serie "Current issues in linguistic theory", vol. 131, Amsterdam / Filadelfia, John Benjamins Publishing Company.

Ibarra Murillo, O. (1998), “Ultzamako hizkeraren deskribapena”. En Camino, Iñaki (ed.), Nafarroako hizkerak. Nafarroako Euskal Dialektologiako Jardunaldietako Agiriak. Iruñea, 1997ko azaroa (24-28), Bilbo, Udako Euskal Unibertsitatea, págs. 89-110.

Ibarra Murillo, O. (2000), Erroibarko eta Esteribarko hizkera, Iruña, Universidad Pública de Navarra. Inza, D. (1922): "Burundako Euskalkia", Euskera III, cuad. 3.

Irigoien, A. (1977): “Gure hizkuntzari euskaldunok deritzagun izenez”, Euskera 22, págs. 513-138.

Irigoien, A. (1988): "Etimología del nombre vasco del vascuence y las vocales nasales vascas escritas por Garibay", Fontes Linguae Vasconum, 56, págs. 139-147.

Irigoien, A. (1997): Opera Selecta, Bilbao, Universidad de Deusto.

Lacombe, G. (1924): "La langue basque". En Meillet, A. y Cohen, M. (dir.), Les langues du Monde, Genève-París, Editions Slatkine, Reimpr. 1981. 
Lafon, R. (1943): Le système du verbe basque au XVI me si cle, 2 vol. Publications de l'Université de Bordeaux, 5. Bordeaux, Delmas. 2 vol, Repr. Donostia-San Sebastián, Elkar, 1980; Donostia / Baiona, Elkar, 1995.

Lafon, R. (1952): "Études basques et caucasiques", Acta Salmanticensia, Filosofía y Letras, 5, págs. 5-91, Salamanca, Universidad de Salamanca.

Laka, I. (1988): "Configurational heads in inflectional morphology: the structure of the inflected forms im Basque”, Anuario del Seminario de Filología Vasca 'Julio de Urquijo’ 22, págs. 343365 .

Laka, I. (1993a): "The structure of inflexion: A case study in Xo syntax". En Hualde, J. I. y Ortiz de Urbina, J. (ed.), Generative Studies in Basque Linguistics, Amsterdam y Philadelphia, John Benjamins, págs. 21-70.

Laka, I. (1993b): "Unergatives that assign ergative". En Bobaljik, J. D. y Philips, C. (ed.), Papers on case and agreemnent 1. MIT Working Papers in Linguistics 18, MIT, Cambridge, Mass., págs. 149-172.

Larramendi, M. de (1729): El impossible vencido. Arte de la lengua bascongada, Salamanca, Antonio Joseph Villagordo Alcaraz, Repr., Donostia-San Sebastián, Hordago, 1979.

Larramendi, M. de (1745): Diccionario trilingüe del castellano, bascuence y latín, San Sebastián, Bartholomé Riesgo y Montero, Donostia-San Sebastián, Pío de Zuazua, $1853^{2^{a} \text { ed. }}$.

Leizarraga, J. [J. Leiçarrague] (1571), Iesus Christ gure Iaunaren Testamentu Berria, La Rochelle, Pierre Hautin. En Linschmann, T. y Schuchardt, H. (eds.), Strasbourg, 1900; Donostia, Hordago, 1979; Bilbao, Euskaltzaidia, 1990.

Martinet, A. (1962): "Le sujet comme fonction linguistigue et l'analysis syntaxique du basque", Bulletin de la Societé Linguistique de Paris 57, París, págs. 73-82.

Meillet, A. (2001): Le méthode comparative en linguistique historique, Oslo, H. Aschehoug y cía. (W. Nygaard), 1925; París, Librairie Honoré Champion, $2^{\mathrm{a}}$ ed., 1970; Metodo Konparatzailea Hizkuntzalaritza Historikoan, J. Gorrotxategi (ed.), Zarautz, Euskal Herriko Unibertsitatea Universidad del País Vasco.

Michelena, L. (1957): "Las antiguas consonantes vascas". En Catalán, D. (ed.), Miscelánea a André Martinet, La Laguna, Tenerife, I, págs. 113-157; , Repr. Michelena, L., Sobre historia de la lengua vasca, Donostia-San Sebástian, Diputación Foral de Guipúzcoa, 1988; Rpr. Michelena, L., "The ancient Basque Consonants". En Hualde, J. I.; Lakarra, J. A. y Trask, R. L. (eds.), Towards a History of the Basque Language, Serie "Current issues in linguistic theory", vol. 131, Amsterdam / Filadelfia, John Benjamins Publishing Company, 1995, págs. 101-135.

Michelena, L. (1953), "Contribución al conocimiento del dialecto roncalés", Boletín de la Real Sociedad Vascongada de Amigos del País IX, San Sebastián, págs. 499-536. Repr. en Michelena, L., Sobre historia de la lengua vasca, Anuario del Seminario de Filología Vasca "Julio de Urquijo", 10, Donostia-San Sebástian, Diputación Foral de Guipúzcoa, 1988, págs. 246-262.

Michelena, L. (1954a), "Nota sobre algunos pasajes de los Refranes y Sentencias de 1596", Boletín de la Sociedad Bascongada de los Amigos del País 10, San Sebastián, págs. 191-199. Repr. en Michelena, Sobre historia de la lengua vasca, Anuario del Seminario de Filología Vasca "Julio de Urquijo", 10, Donostia-San Sebástian, Diputación Foral de Guipúzcoa, II, 1988, págs. 792798.

Michelena, L. (1954b), "La posición fonética del dialecto vasco del Roncal", Vía Domitia III, Toulouse, Anales publiées par la Faculté des Lettres de Toulouse, págs. 124-158. Repr. en Michelena, L., Sobre historia de la lengua vasca, Anuario del Seminario de Filología Vasca "Julio de Urquijo", 10, Donostia-San Sebástian, Diputación Foral de Guipúzcoa, 1988, págs. 273-297. 
Michelena, L. (1954c), "Notas fonológicas sobre el salacenco", Boletín de la Sociedad Bascongada de los Amigos del País 10, San Sebastián, págs. 191-199. Repr. Anuario del Seminario de Filología Vasca "Julio de Urquijo, 1, Donostia-San Sebastián, Diputación Foral de Guipúzcoa, II, 1967, págs. 163-177. Repr. en Michelena, Palabras y textos, Vitoria, Universidad del País Vasco, 1987, págs. 87-140.

Michelena, L. (1954d), "De onomástica aquitana", Pirineos, 10, pp. 409-458. Repr., Michelena, Lengua e historia, Madrid, Paraninfo, 1985, págs. 409-445.

Michelena, L. (1961): Fonética histórica vasca, Donostia-San Sebastian, Diputación Foral de Guipúzcoa, $2^{\mathrm{a}}$ ed., 1977, $3^{\mathrm{a}}$ ed., 1985.

Michelena, L. (1963): Lenguas y protolenguas, Acta Salmanticensis, Filosofía y Letras, t. XVII, 2, Salamanca, Universidad de Salamanca, Repr. Donostia - San Sebastián, Anuario del Seminario de Filología Vasca 'Julio de Urquijo', 20, 1990.

Michelena, L. (1964a): Textos arcaicos vascos, Madrid, Repr. Donostia - San Sebastián, Diputación Foral de Guipúzcoa, Anuario del Seminario de Filología Vasca 'Julio de Urquijo', 11, 1989.

Michelena, L. (1964b): Sobre el pasado de la lengua vasca, San Sebástian, Editorial Auñamendi. Repr. en Sobre historia de la lengua vasca, Anuario del Seminario de Filología Vasca "Julio de Urquijo", 10, Donostia-San Sebástian, Diputación Foral de Guipúzcoa, 1988.

Michelena, L. (1974): "El elemento latino-románico en la lengua vasca", Fontes Linguae Vasconun VI, 17, Pamplona, págs. 183-209. Repr. Michelena, L., Palabras y textos, Vitoria, Universidad del País Vasco, 1987, págs. 195-219.

Michelena, L. (1982): "Tipología en torno a la lengua vasca", Anuario del Seminario de Filología vasca “Julio de Urquijo”, XVI, págs. 157-170. Rpr. en Michelena, Luis, Palabras y textos, Vitoria, Universidad del País Vasco, 1987, págs. 23-33.

Michelena, L. y Sarasola, Ibon (1988): Textos arcaicos vascos. Contribución al estudio y edición de textos antiguos vascos, Anuario del Seminario de Filología Vasca "Julio de Urquijo", 10, Donostia-San Sebástian, Gipuzkoako Foru Aldundia - Diputación Foral de Guipúzcoa, Euskal Herriko Unibertsitatea - Universidad del País Vasco.

Micoleta, R. (1653): Modo breve para aprender la lengua vizcayna, Dorca, Gerona, 1880; Repr. Barcelona, Ed. Fita, 1888. Repr. A. Zelaieta (ed.), Hizkuntza eta Literatura 7, 1988.

Montague, R. (1973): Ensayos de filosofía formal, Madrid, Alianza Universidad, 1977, págs. 158-182.

Oihenart, A. d' (1656): Notitia utriusque Vasconiae tum Ibericae tum Aquitanicae, Paris, $2^{\mathrm{a}}$ ed., 1656. Trad. Esp. de la $2^{\mathrm{a}}$ ed. por Gorosterratzu, J., Revista Internacional de los Estudios Vascos 17-19, 1926-1928; Repr. por Ciérvide R. con traducción e introducción de Gorosterratzu, sobre la $2^{\mathrm{a}}$ ed., (1656, París), que tiene más datos gramaticales, en Revista Internacional de Estudios Vascos XVII, XVIII, XIX, Vitoria-Gasteiz, Parlamento Vasco, 1992.

Oregi Aranburu, J. (1974): "Euskal-aditzaz zenbait gogoeta", Fontes Linguae Vasconum, 17, Pamplona, págs. 265-283.

Partee, B. H.; Meulen, A. T.; Wall, R. E. (1990): Mathematical methods in lingüístics, en Studies in linguistics and philosophy, v. 30, Dordrecht / Boston / London, Kluwert Academic Publishers.

Rebuschi, G., (1984): Structure de l'énoncé en basque, Paris, Société d'Etudes Linguistiques et Anthropologiques de France.

Rebuschi, G. (1997): Essais de Linguistique Basque, Anuario del Seminario de Filología Vasca 'Julio de Urquijo’ 35, Donostia - San Sebastián, Gipuzkoako Foru Aldundia - Diputación Foral de Guipúzcoa.

Refranes y sentencias comunes en bascuence, declaradas en romance con números sobre cada palabra, para que se entiendan las dos lenguas (1596), Pamplona, P. Porralis de Amberes; Repr. Lakarra, J. A., Refranes y Sentencias, (1596). Ikerketa eta edizioa, Bilbo, Euskaltzaindia, 1996. 
Rijk, R. P. O. de (1992): “'Nunc' Vasconice”, Anuario del Seminario de Filología Vasca 'Julio de Urquijo’ 26.3, Donostia - San Sebastián, Gipuzkoako Foru Aldundia - Diputación Foral de Guipúzcoa, págs. 695-724. Repr. " 'Nunc' in Old Basque". En Hualde, J. I.; Lakarra, J. A. y Trask, R. L. (eds.), Towards a History of the Basque Language, Serie "Current issues in linguistic theory", vol. 131, Amsterdam / Filadelfia, John Benjamins Publishing Company, 1995, págs. 295-311.

Rotaetxe, K. (1978a): "Lingüística - Lógica. La construcción ergativa vasca", Revista Española de Lingüística 8.2, Madrid.

Rotaetxe, K. (1978b): Estudio estructural del euskara de Ondárroa, Durango, Leopoldo Zagaza Editor.

Rotaetxe, K. (1980): “Ergatiboaren Sujetotasuna”, Euskera 25.2, Bilbo, págs. 417-424.

Sarasola, I. (1983): "Contribución al estudio y edición de textos antiguos vascos", Anuario del Seminario de Filología Vasca 'Julio de Urquijo', Donostia - San Sebastián, Diputación Foral de Guipuzcoa / Universidad del País Vasco, págs. 69-212. Repr. Donostia - San Sebastián, Diputación Foral de Guipuzcoa, 1990.

Saussure, F. de (1916): Curso de lingüística general, Buenos Aires, Ed. Losada, 16a ed., 1977.

Schuchardt, H. (1893): Baskische Studien über die Enststehung der Bezugsformen des baskischen Zeitworts, Wien, F. Tempsky; Denkschriften der K.K. Akademie der Wissenschaften 43, Wirklichen Mitglieder des Kais. Akademie der Wissenchaften, Wien. Repr. Goenaga, A. (Trad.), "Sobre la formación de las flexiones de relación del verbo vasco", Boletín de la Real Sociedad Vascongada de Amigos del País XXVIII, 2/3, París - San Sebastián, 1972, págs. 217-337.

Schuchardt, H. (1923): Primitiae Linguae Vasconum. Einführung ins Baskische, Salamanca, Universidad de Salamanca, 1947.

Serrano, S. (1977): Lógica, lingüística y matemáticas, Barcelona, Ed. Anagrama.

Tarski, A. M. (1972). La concepción semántica de la verdad y los fundamentos de la semántica, Buenos Aires, Nueva Visión. Edición en español de "The concept of truth in formalized languages", Logic, semantics, metamathematics, Papers from 1923 to 1938, Oxford, Clarendon Press, 1956.

Trask, R. L. (1977): "Historical syntax and Basque verbal morphology: Two hypotheses". En Douglas, W. A.; Etulain, R. W. y Jacobsen, W.H. (eds.), Anglo-American contributions to Basque stydies. Essays in honor of Jon Bilbao, Reno, Univ. of Nevada, págs. 203-217.

Trask, R. L. (1979): "On the origins of Ergativity”, en F. Plank (ed.), Ergativity. Towards a Theory of Grammatical Relations, London / New York / Toronto / Sydney / San Francisco, Academic Press , págs. 385-404.

Trask, R. L. (1990): "The $-n$ class of verbs in Basque", Transactions of the Philological Society 88:1, págs. 111-128.

Trask, R. L. (1995): "Origin and relatives of the Basque language. Review of the evidence", en J. I. Hualde, J. A. Lakarra y R. L. Trask (ed.), págs. 207-234.

Trask, R. L. (1995): "On the history of the non-finite verb forms in Basque". En Hualde, J. I.; Lakarra, J. A. y Trask, R. L. (eds.), Towards a History of the Basque Language, Serie "Current issues in linguistic theory", vol. 131, Amsterdam / Filadelfia, John Benjamins Publishing Company, 1995, págs. 207-234.

Trask, R. L. (1997): The History of Basque, London and New York, Routledge.

Txillardegi [Álvarez Emparantza, J. L.] (dir.) (1983): Euskal Dialektologiaren Hastapenak, Iruñea Pamplona, Udako Euskal Unibertsitatea.

Uhlenbeck, C. C. (1922): "Le caractère passif du verbe transitif ou du verbe d'action dans certains langues de l'Amerique du Nord", Revista Internacional de Estudios Vascos XIII, París - San Sebastián , págs. 399-419. 
Uhlenbeck, C. C. (1947): “Affinités prouvées e presumées de la langue basque”, Eusko-Jakintza, Revue des études basques - Revista de estudios vascos, I, Bayona.

Yrízar, P. de (1947): "Formación y desarrollo del verbo auxiliar vasco", San Sebastián, Boletín de la Real Sociedad Vascongada de Amigos del País, año III, 4, San Sebastián, págs. 427-494.

Yrízar, P. de (1973): "Los dialectos y variedades de la lengua vasca", Anuario del Seminario de Filología Vasca 'Julio de Urquijo', VII, Donostia - San Sebastián, págs. 3-37.

Yrízar, P. de (1975): “Aditza euskalki guztietan (Arloaren adierazten)”, Euskera XX, págs. 407-451.

Yrízar, P. de (1981): Contribución a la dialectología de la lengua vasca, 2 Tomos, Donostia - San Sebastián, Caja de Ahorros Provincial de Guipúzcoa.

Yrízar, P. de (1992a): Morfología del verbo auxiliar vizcaíno (Estudio dialectológico), Bilbao, Bilbo Bizkaiko Kutxa - Euskaltzaindia.

Yrízar, P. de (1992b): Morfología del verbo auxiliar altonavarro septentrional (Estudio dialectológico), Bilbao, Bilbo Bizkaiko Kutxa - Euskaltzaindia.

Yrízar, P. de (1992c): Morfología del verbo auxiliar altonavarro meridional (Estudio dialectológico), Bilbao, Bilbo Bizkaiko Kutxa - Euskaltzaindia.

Yrízar, P. de (1992d): Morfología del verbo auxiliar roncalés (Estudio dialectológico), Bilbao, Bilbo Bizkaiko Kutxa - Euskaltzaindia.

Yrízar, P. de (1997): Morfología del verbo auxiliar labortano (Estudio dialectológico), Bilbao, Bilbo Bizkaiko Kutxa - Euskaltzaindia.

Yrízar, P. de (1999): Morfología del verbo auxiliar bajonabarro occidental (Estudio dialectológico), Bilbao, Bilbo Bizkaiko Kutxa - Euskaltzaindia.

Yrízar, P. de (2002): Morfología del verbo auxiliar bajonabarro oriental (Estudio dialectológico), Bilbao, Bilbo Bizkaiko Kutxa - Euskaltzaindia.

Zuazo, K. (1998a): "Nafarroako euskal hizkerak". En Camino, I. (ed.), Nafarroako hizkerak. Nafarroako Euskal Dialektologiako Jardunaldietako Agiriak. Iruñea, 1997ko azaroa (24-28), Bilbo, Udako Euskal Unibertsitatea, págs. 1-22.

Zuazo, K. (1998b): "Euskalkiak, gaur”, Fontes Linguae Vasconum, nº 78, pp. 191-234. 